\title{
MIGRACIÓN RESIDENCIAL Y URBANISMO EXPANSIVO EN EL MEDITERRÁNEO ESPAÑOL
}

\author{
Joan Carles Membrado Tena \\ Universidad de Valencia
}

\section{RESUMEN}

Este artículo investiga la migración internacional de jubilados noreuropeos hacia España y su influencia en el desarrollo del urbanismo expansivo en nuestro país. Los temas clave que en este artículo se analizan son la expansión del urbanismo expansivo durante la burbuja inmobiliaria española, la cantidad y distribución de los jubilados noreuropeos residentes en España, y la relación entre la llegada de dichos migrantes residenciales y la difusión del urbanismo expansivo. Este artículo explica los motivos de esta migración residencial, que están principalmente relacionados con el clima y el estilo de vida mediterráneos. También describe los beneficios y los inconvenientes de dicha migración residencial y el impacto medioambiental y paisajístico sobre la España Mediterránea.

Palabras clave: migración residencial, urbanismo expansivo, burbuja inmobiliaria, España Mediterránea.

\section{Residencial migration and urban sprawl in the spanish mediterranean area}

\begin{abstract}
This paper investigates the international retirement migration from elderly Europeans into Spain and its influence on expansion of urban sprawl there. Key themes analyzed in this paper include the urban sprawl expansion during the Spanish housing bubble, the size and distribution of the elderly Europeans residents in Spain, and the link between lifestyle migrants and urban sprawl development. This paper considers the reasons for elderly Europeans moving into Spain, which are chiefly related with the weather and lifestyle. It also explores the benefits and drawbacks of these en masse lifestyle migration and the environmental and landscape impacts on Mediterranean Spain.
\end{abstract}

Key words: lifestyle migrants, urban sprawl, housing bubble, Mediterranean Spain.

Recibido: 15 de noviembre de 2013

Devuelto para su revisión: 20 de marzo de 2014

Aceptado: 30 de abril de 2014

Departamento de Geografía. Universidad de Valencia. Avda. Blasco Ibáñez, 28. 46010 VALENCIA (España). E-mail: joan.membrado@uv.es 


\section{INTRODUCCIÓN}

En este artículo se analiza, por un lado, la reciente migración residencial de jubilados noreuropeos hacia el Mediterráneo español y, por otro, los efectos de dicha migración sobre el exagerado desarrollo del urbanismo expansivo en esta región. En los últimos años se han publicado varios trabajos sobre el efecto de las migraciones en los cambios de usos del suelo (Entwisle y Stern, 2005; Lambin y Geist, 2006; Sherbinin et al., 2007). Walker y Solecki (2004) y Kambly y Moreland (2009) examinaron los daños medioambientales en la península de la Florida ligados a la migración residencial de jubilados. Crawford et al. (2013) investigan el cambio de usos del suelo en el litoral de Carolina del Norte debido a la migración residencial. Este artículo también analiza los efectos económicos, sociales y medioambientales derivados de este reciente auge del urbanismo expansivo, estimulado por la demanda solvente de migrantes residenciales noreuropeos, favorecido por los distintos gobiernos de España, y promovido por entidades bancarias y grandes empresas de la construcción. Hof y Blázquez (2013) analizan los vínculos entre el turismo inmobiliario y el urbanismo expansivo en la isla de Mallorca.

Gracias a la riqueza virtual generada por la burbuja inmobiliaria (1998-2007), España atrajo numerosa inmigración durante la primera década del siglo XXI. Antes de 1980, España había sido un país de emigrantes, pero entre 1998 y 2010 llegaron a nuestro país más de 5 millones de inmigrantes (Hierro y Maza, 2010; Laparra, 2011; Módenes et al., 2013), lo que lo convirtió en uno de los estados europeos en los que residía una mayor proporción de expatriados (12,2\% en 2010). Sin embargo, debido a la crisis económica actual, España ha perdido más de 200.000 trabajadores extranjeros solo en 2012, y muchos jóvenes españoles cualificados también se han visto obligados a emigrar.

Más del $80 \%$ de los emigrantes que llegaron a España huían de la pobreza y buscaban mejores condiciones laborales. Se trata de los migrantes por trabajo. Sin embargo, algo menos del $20 \%$ - casi la mitad de ellos, jubilados - no venían huyendo de la pobreza, ya que procedían de países más ricos que España, sino que perseguían una mejora de su estilo y calidad de vida en un lugar cálido y soleado, cercano al mar y no muy lejos (2-3 horas en avión) de sus fríos y lluviosos países de origen. Se trata de los llamados migrantes residenciales, traducción no literal empleada por Huete y Mantecón $(2011,2013)$ de lyfestyle migrants, que es el término usual en el mundo anglosajón (Oliver, 2007; Benson y O’Reilly, 2009).

El crecimiento reciente de la migración residencial deriva del auge del turismo de masas en el Mediterráneo. El aumento de la riqueza y la esperanza de vida que tuvo lugar a partir de 1960 incrementó el número de pensionistas noreuropeos que podían permitirse veranear junto al mar Mediterráneo (Russell et al., 1998). A partir de la década de 1990 se produjo un gran aumento de la migración residencial, debido al creciente flujo de noreuropeos muchos de ellos jubilados - que decidieron establecer su residencia permanente en las regiones mediterráneas (King et al., 2000; O'Reilly, 2000, 2007; Williams et al., 2000; Gustafson, 2009; Rodríguez et al., 1998, 2004, 2005; Casado, 2006; Huete, 2009; Mazón et al., 2009).

En el caso del Mediterráneo español, desde 1970 la planificación del uso del suelo se llevó a cabo teniendo como objeto servir a los intereses turísticos (Navalón, 1995; Vera y Ivars, 2003; Mazón, 2006; Huete y Mantecón, 2011). Pero fue durante la expansión económica mundial de finales del siglo XX y principios del XXI cuando muchos de los 
turistas noreuropeos decidieron residir permanentemente en España y empadronarse allí, gracias a una serie de factores como la aparición de compañías aéreas de bajo precio, el progreso notable de las infraestructuras, los precios de la vivienda relativamente bajos, o la mejora tecnológica global. Durante ese periodo España pasó de albergar menos de 60.000 migrantes residenciales (mayores de 55 años) en 1991 a casi 450.000 en 2011. La crisis económica actual ha condicionado que en 2012 haya descendido por primera vez en décadas el número de migrantes residenciales jubilados.

Probablemente esta masiva migración de noreuropeos hacia España haya sido el flujo más importante de migración internacional de jubilados en todo el mundo durante los últimos 15 años. Otros flujos significativos han sido los de noreuropeos hacia otros países mediterráneos como Portugal, Italia, Francia, Malta, Grecia y Chipre, estudiados por Russell y Patterson (1998), Warnes y Patterson (1998) y Williams y Patterson (1998); los del Reino Unido hacia los sunshine states de EEUU, Malasia, Tailandia o Australia; los de Canadá hacia los sunshine states de EEUU; y los de EEUU hacia el Caribe. Es interesante comparar la migración desde el frío y húmedo norte de Europa hacia los cálidos países mediterráneos (sobre todo hacia España) con otra migración (esta no internacional) desde el norte hacia el sur de EEUU, sobre todo hacia Florida, que ha sido durante el último cuarto del siglo Xx el destino preferido por los jubilados estadounidenses para retirarse (Walters, 2002; Smith y House, 2006).

Por lo que respecta a la integración social y cultural de los cientos de miles de jubilados emigrados en la sociedad española hay que decir que esta es escasa. Las barreras lingüísticas y culturales dificultan la interacción entre los residentes españoles y los noreuropeos, y generan procesos de fragmentación social (O’Reilly, 2009). Sin embargo, conforme las colonias de expatriados van creciendo, se produce un efecto llamada hacia muchos jóvenes de su misma nacionalidad, que también vienen a España como migrantes residenciales con el fin de proporcionar servicios para las colonias de jubilados. De esta manera, las comunidades de inmigrantes de edad avanzada acaban siendo más autosuficientes y con menor necesidad de integrarse.

Estos migrantes residenciales jubilados han contribuido al cambio de uso del suelo en el Mediterráneo español, al haber estimulado el urbanismo expansivo, ya que la gran mayoría quería - y podía pagar - una vivienda unifamiliar, siguiendo los patrones urbanos propios de sus países de origen (en su mayoría el Reino Unido, Alemania, Escandinavia y el Benelux). Si analizamos los cambios recientes de usos del suelo en España, podemos ver que los suelos urbanos han experimentado un fuerte aumento, especialmente durante la burbuja inmobiliaria española (1997-2007) (Burriel, 2008, 2009a y 2009b; Gaja, 2008; Romero, 2010; Rullán, 2011); y también que entre los suelos urbanos el que más crece es el urbanismo expansivo o urban sprawl (Gillham, 2002; Richardson y Chang Hee, 2004; o Hogan y Ojima, 2008), un modelo de desarrollo urbano poco extendido en el sur de Europa antes de la década de 1990 (Muñoz, 2003; Pumain, 2004; Roca et al., 2004).

\section{METODOLOGÍA}

El objetivo principal de este artículo es analizar la vinculación causal entre la migración residencial de jubilados noreuropeos y el urbanismo expansivo en la costa 
Mediterránea española. Un segundo objetivo es evaluar las ventajas e inconvenientes socioambientales que ha provocado este reciente fenómeno migratorio.

Con el fin de distinguir migrantes por trabajo de migrantes residenciales, a partir de los datos del Instituto Nacional de Estadística, hemos tenido en cuenta su país de origen: si este posee un mayor PIB per cápita que España consideramos a los migrantes como residenciales, y si posee menor PIB per cápita los definimos como migrantes por trabajo. Para estudiar el fenómeno de la migración internacional de jubilados hacia el litoral mediterráneo español analizamos los datos del INE sobre migrantes residenciales empadronados en España de más de 55 años, edad que la mayoría de estudiosos consideran el umbral entre la población activa y la jubilada y prejubilada (Koch, 2008: 24). Cabe señalar que casi la mitad de los migrantes residenciales son mayores de 55 años, mientras que entre los migrantes por trabajo el número de jubilados es insignificante. Además, el 95\% de los migrantes residenciales jubilados se ha instalado en la España litoral de clima mediterráneo, buscando las zonas costeras y de clima más benigno, y también el estilo de vida mediterráneo, con un ritmo de vida más lento de vida y más actividades al aire libre.

Hemos utilizado asimismo dos SIG para el estudio de la evolución del uso del suelo en España. El primero es CORINE Land Cover (CLC), proyecto gestionado por la Agencia Europea de Medio Ambiente (European Environmental Agency) cuyo objetivo es obtener información sobre el medio ambiente y las políticas territoriales en Europa. Su primera versión data de 1990 (aunque para España las ortofotos corresponden a 1987), y fue actualizado en 2000 y 2006. La nomenclatura CORINE consta de 44 usos del suelo. 11 de ellos se refieren a usos artificiales, entre los cuales el denominado tejido urbano discontinuo (código 112), que se corresponde con el suelo urbano expansivo o urban sprawl. Un segundo SIG que hemos empleado en este artículo (solo con fines estadísticos para algunas comarcas del litoral mediterráneo) es SIOSE (Sistema de Información de Ocupación del Suelo en España), un proyecto impulsado por el Instituto Geográfico Nacional, mucho más preciso que CORINE (IGN, 2006; Membrado, 2011), realizado en 2005, y actualizado en 2009 y en 2011.

El programa de diseño cartográfico utilizado para crear los mapas de este artículo ha sido ArcGIS de ESRI (Environmental Systems Research Institute). Para crear los mapas de España hemos utilizado datos a nivel provincial, y para los mapas del litoral mediterráneo, datos a escala comarcal o supracomarcal.

\section{ANTECEDENTES}

\subsection{La burbuja inmobiliaria española}

Entre 1997 y 2007 el crecimiento económico de España se basó en el sector de la construcción. El boom inmobiliario español alcanzó su punto máximo en 2006, año en que se construyeron más viviendas que la suma de las construidas en Italia, el Reino Unido y Alemania, tres países más poblados y más ricos que España. ${ }^{1}$ Este auge de la vivienda se

1 Según la European Mortgage Federation en ese año se construyeron 760.168 casas en España, más que la suma de las construidas en Italia (261.455), el Reino Unido (230.330) y Alemania (249.436) (EMF, 2009: 75-76). Por cada 1.000 habitantes, en España se construyeron entonces cerca de 18 casas, mientras que en Italia eran 4,5 las construidas para el mismo número de personas, 3,8 en el Reino Unido y 3 en Alemania (EMF, 2009: 9). 


\section{Figura 1 \\ EVOLUCIÓN DE LA CONSTRUCCIÓN DE NUEVA VIVIENDA EN ESPAÑA (1990-2011)}

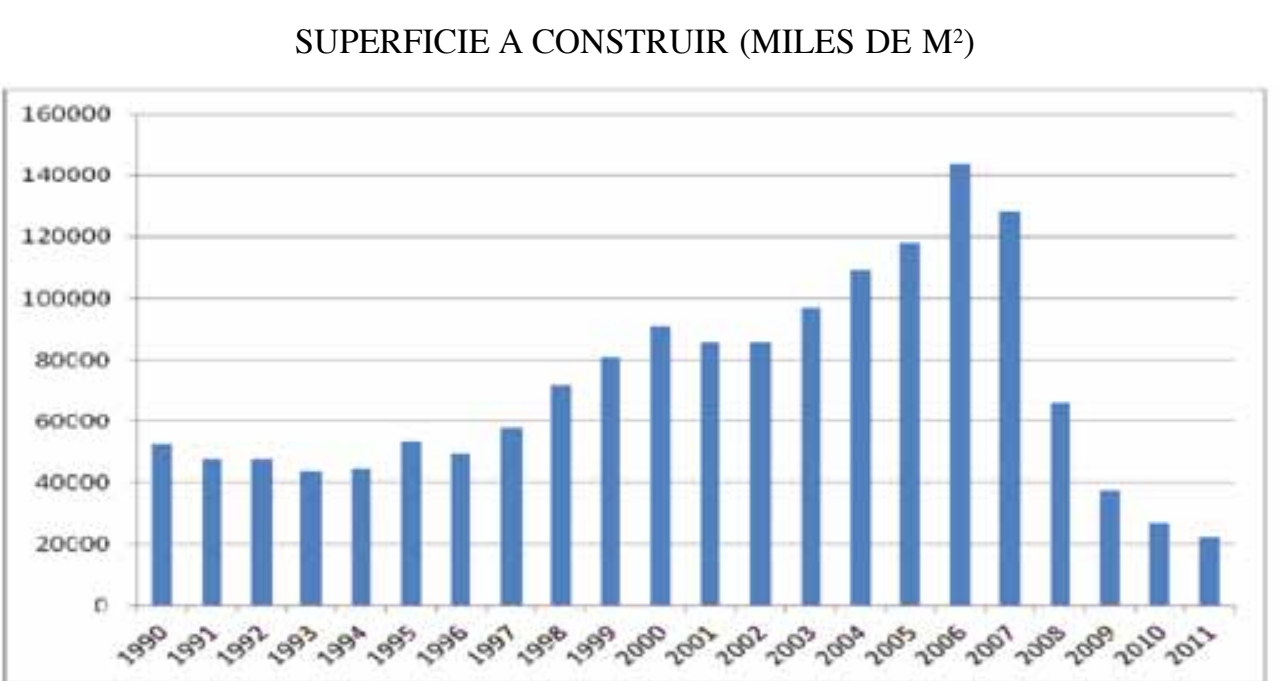

Fuente: elaboración propia a partir de datos de INE (Instituto Nacional de Estadística). (http://www.ine.es/jaxi/ tabla.do?path=/t07/a081/a1998/10/\&file=lm60001.px\&type=pcaxis\&L=0).

puede explicar por dos factores principales. El primero es que España, en tanto que miembro de la zona euro desde su creación en 1999, disfrutó de los beneficios de ser parte de una divisa considerada fuerte y segura (Romero, 2010: 24). Así fue fácil para los bancos y empresas españolas obtener crédito en el extranjero. El segundo es la aprobación en 1998 de una nueva Ley del Suelo, que establecía que cualquier suelo no protegido era edificable (Rullán, 2011: 182). La conjunción de ambos factores dio lugar a una considerable inversión de capital privado (tanto español como extranjero) en el sector de la vivienda, que ofrecía pingües y rápidos beneficios. Los ayuntamientos comenzaron a promover la expansión urbana con el fin de utilizarla como fuente de ingresos mediante impuestos. La falta de un marco regulatorio adecuado permitió a los promotores privados construir tanto como quisieran. Ni las autoridades estatales ni las autonómicas fueron capaces de controlar ese desarrollo urbano promovido por los municipios y los intereses privados, o de atenuar su impacto en la sostenibilidad territorial (Burriel, 2008).

Este proceso de expansión inmobiliaria se vio reforzado por el crédito barato, gracias a los bajos tipos de interés que los bancos cobraban por los préstamos para comprar una vivienda. Impulsado el empleo por la fiebre de la construcción, el número de desempleados en España pasó del $21 \%$ en 1997 a solo el 8\% en 2006. El crecimiento de la ocupación atrajo a mucha mano de obra inmigrante ${ }^{2}$ e incrementó el ingreso disponible de muchas familias españolas, dos factores que comportaron que más personas quisieran comprar una primera o segunda residencia en propiedad.

2 La población inmigrante pasó del 1\% de la población residente en España en 1995 al 12,2\% en 2010. 


\section{Figura 2 \\ DESARROLLO DEL TEJIDO URBANO DISCONTINUO EN ESPAÑA POR PROVINCIAS (1987-2006) SEGÚN DATOS DE CORINE LAND COVER (EUROPEAN ENVIRONMENT AGENCY)}

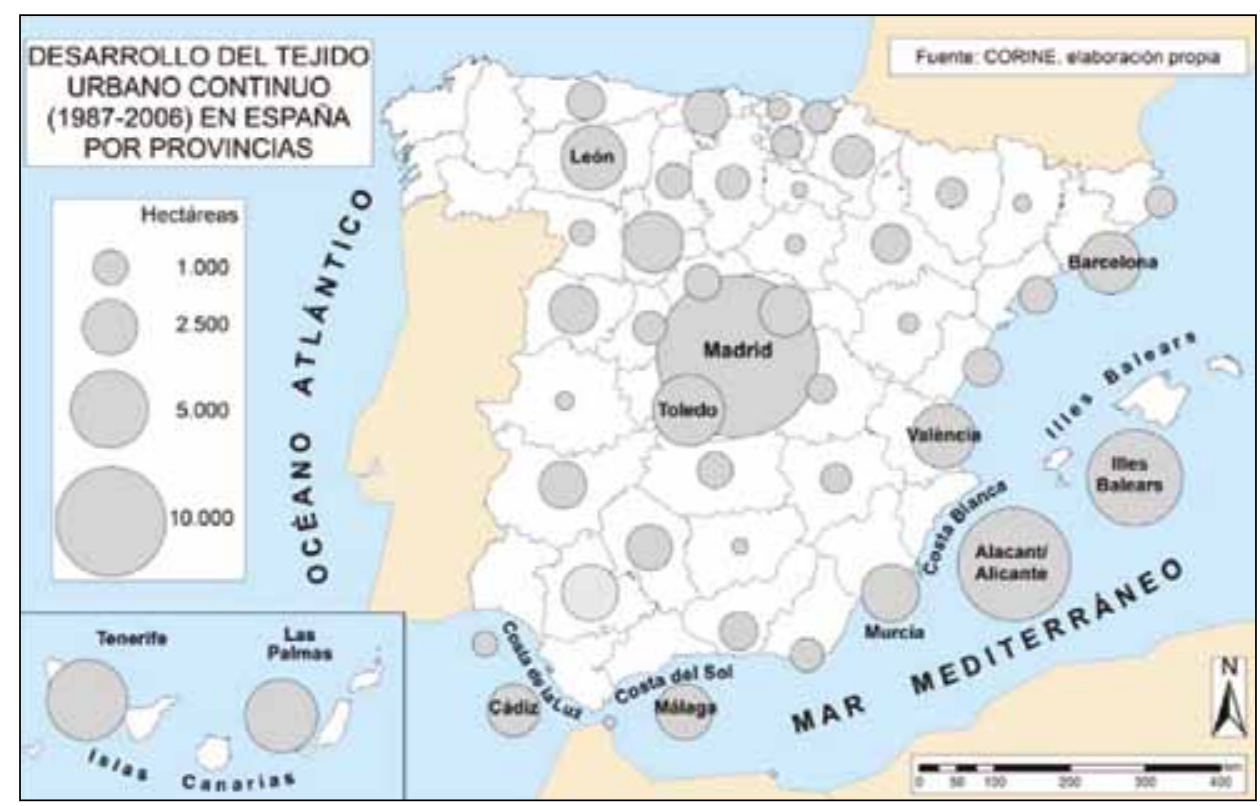

Fuente: CORINE Land Cover (no hay datos fiables de Galicia).

El precio medio de la vivienda se multiplicó por tres en España entre 1997 y 2007 debido a la burbuja inmobiliaria especulativa, que en 2007 estalló a causa de la crisis financiera mundial. Las líneas de crédito se redujeron entonces, provocando el colapso del sector de la construcción e inmobiliario. Desde ese momento, los precios de la vivienda han caído en España en un tercio, y la construcción residencial ha descendido a niveles de 1960.

La quiebra del sistema económico español imperante entre 1997 y 2007, basado en el uso especulativo de los inmuebles como activo financiero (financiarización), ha supuesto un endeudamiento familiar y del Estado sin precedentes, que se ha traducido en el rescate de la banca española. Este proceso ha estado plagado de corrupción urbanística por parte de aquellos que se quisieron enriquecer con el urbanismo, en general, y con el urbanismo expansivo en particular (López y Rodríguez, 2010: 17).

\subsection{Urbanismo expansivo en España}

El urbanismo expansivo, caracterizado por las viviendas unifamiliares y la baja densidad edificatoria, ha sido el modelo de desarrollo urbano que más ha crecido en España durante los últimos 20 años, particularmente en Madrid y en la costa mediterránea (figura 2). Se desarrolló en EEUU en la década de 1950; se propagó al norte de Europa en la 
década siguiente; poco después llegó a Francia; ${ }^{3}$ y finalmente afectó a España, Italia y otros países mediterráneos, que hasta los años 1990 habían sido un paradigma de desarrollo urbano compacto, complejidad urbana y diversidad social (Muñoz, 2003: 381; Roca et al.: 2004). Durante la década de 2000 el uso del automóvil creció más rápido en Europa que en EEUU, lo que puede relacionarse con el rápido crecimiento urbano expansivo, a pesar de la aplicación de algunas políticas pro-ciudad compacta en el viejo continente (Richardson y Chang Hee, 2004: 7).

Los defensores del urbanismo expansivo argumentan que vivir en un área suburbana aumenta el contacto con la naturaleza y reduce la congestión del tráfico y la contaminación atmosférica. Además, defienden que las viviendas suburbanas son más baratas que las urbanas y que, cuando se le pregunta, la mayoría de la gente prefiere vivir lejos de la ciudad compacta (Gillham, 2002: 72). Los detractores del urbanismo expansivo consideran que devora gran cantidad de suelo (cultivos, zonas húmedas, forestales) y destroza el paisaje. Además, consume cantidades insostenibles de energía y agua. La dependencia del uso del vehículo privado que caracteriza este modelo no sólo contamina más y congestiona el tráfico, sino que además fomenta la obesidad y el estrés de los conductores. Además, destruye la vida comunitaria y segrega a las personas en función de su nivel de renta (Gillham, 2002: 72).

Entre las causas que arrastran a la gente desde las ciudades compactas hacia las dispersas o suburbanas se encuentra el precio de la vivienda. Aquellos que quieren comprar una casa grande pueden encontrar opciones más económicas en los suburbios, donde, además, se supone que gozarán de ventajas ambientales y sociales. Hogan y Ojima (2008: 205) consideran que el desarrollo del urbanismo expansivo está ligado a nuevos fenómenos tales como el ambientalismo, las tecnologías de la comunicación, la economía globalizada y las expectativas de consumo.

\section{RELACIÓN ENTRE MIGRANTES RESIDENCIALES Y URBANISMO EXPANSIVO}

\subsection{Migrantes residenciales en el Mediterráneo español}

Hay que distinguir entre dos tipos principales de inmigrantes en España. En primer lugar, los que vienen de un país más pobre (es decir, con un PIB per cápita más bajo que el español). Estos son los migrantes por trabajo. Son más del $80 \%$ del total y provienen principalmente de Europa del Este, América del Sur y África del Norte (fig. 3). Llegaron a España huyendo de la pobreza, esperando encontrar trabajo (si encuentran uno, sin embargo, es como asalariado) y mejores condiciones de vida (fig. 5). En segundo lugar, hay cerca de un $20 \%$ de migrantes cuyo origen son países más ricos (esto es, con un PIB per cápita más alto que el español), tales como el Reino Unido, Alemania, el Benelux o Escandinavia (fig. 4). Se trata de los migrantes residenciales. Para ganarse la vida dependen de sus pensiones y ahorros, si son jubilados. Si no lo son, por lo general son trabajadores por cuenta propia, que a menudo prestan servicios para los jubilados de su misma nacionalidad (fig.

3 Donde el suelo urbano expansivo se multiplicó por cinco entre 1969 y 1999 (Pumain, 2004: 137). 


\section{Figura 3 \\ ESPAÑA: PRINCIPALES PAÍSES DE PROCEDENCIA DE LOS INMIGRANTES EMPADRONADOS (2012)}

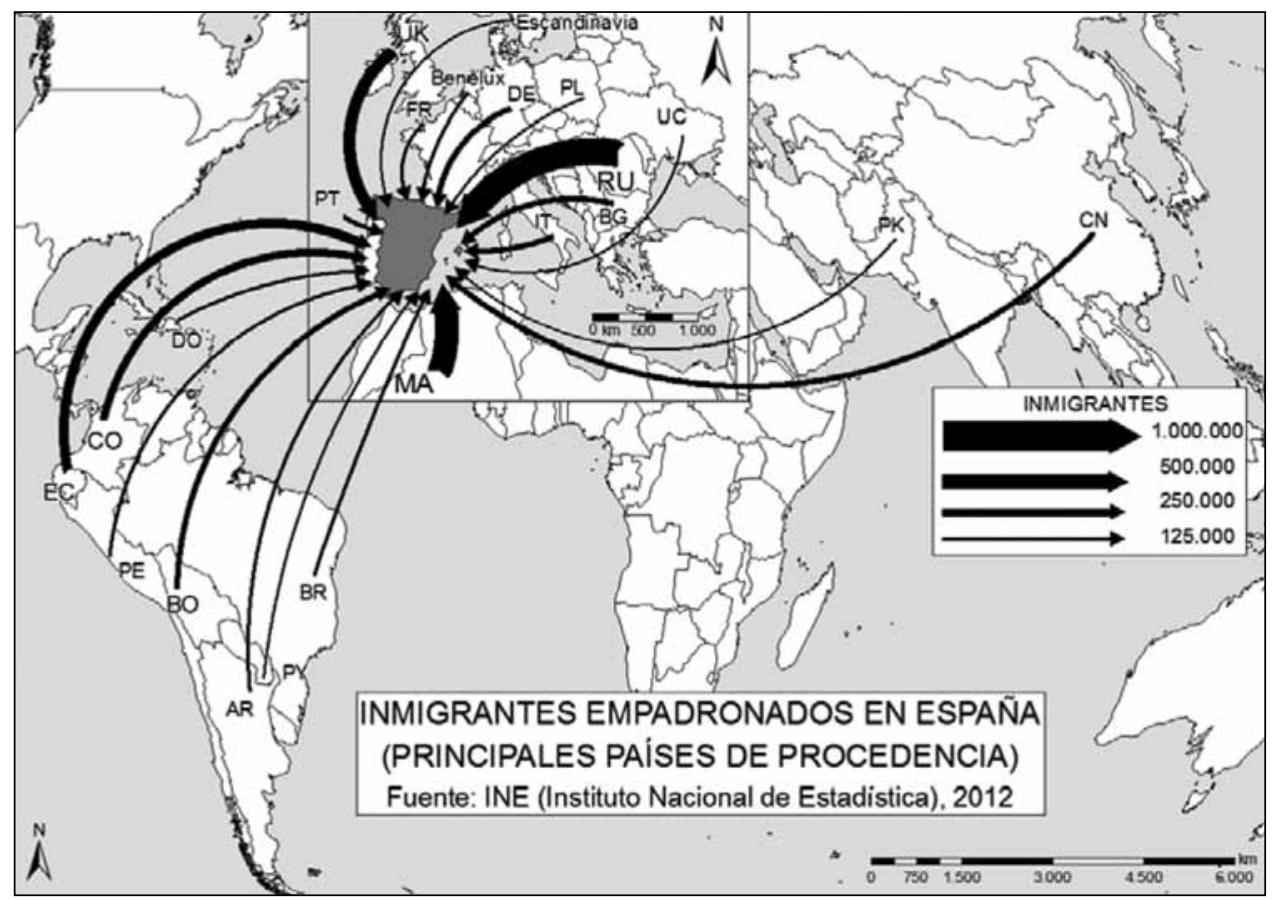

Fuente: INE (Instituto Nacional de Estadística). (http://www.ine.es/jaxi/tabla.do?path=/t20/e245/p04/a2012/ $10 / \&$ file $=00000008$.px \& type $=$ pcaxis $\& \mathrm{~L}=0$ )

5). En ambos casos son personas relativamente acomodadas de todas las edades, que han inmigrado a tiempo parcial o a tiempo completo a lugares que, por diversas razones, significan, para el migrante, una mejor calidad de vida, según Benson y O’Reilly (2009: 609).

La mayoría de los migrantes residenciales decidió establecerse a lo largo de la costa mediterránea española por diversas razones, entre las cuales se cuentan el clima, las playas, la gastronomía, el vino, las fiestas, el ritmo de vida sosegado y la vida al aire libre. Y también porque pudieron costearse una vivienda unifamiliar a un precio no demasiado alto. Además, hay que tener en cuenta el papel de las autoridades políticas españolas, al apoyar el turismo de masas e intentar atraer a potenciales compradores extranjeros de viviendas en la costa, y también el de los promotores (tanto españoles como extranjeros). Dichos promotores son responsables de la concentración de extranjeros de la misma nacionalidad en ciertas áreas. Con el fin de lograr la optimización de recursos y costes, los promotores trataron de vender cada urbanización en un solo país, creando así colonias de personas de un mismo origen. Estos asentamientos por nacionalidad eran especialmente apetecibles para la gente mayor, que encontraba más seguro moverse en el extranjero si podía vivir entre sus compatriotas (Huete, 2005). 
Figura 4

\section{COSTA BLANCA: PRINCIPALES PAÍSES DE PROCEDENCIA DE LOS INMIGRANTES} EMPADRONADOS (2012)

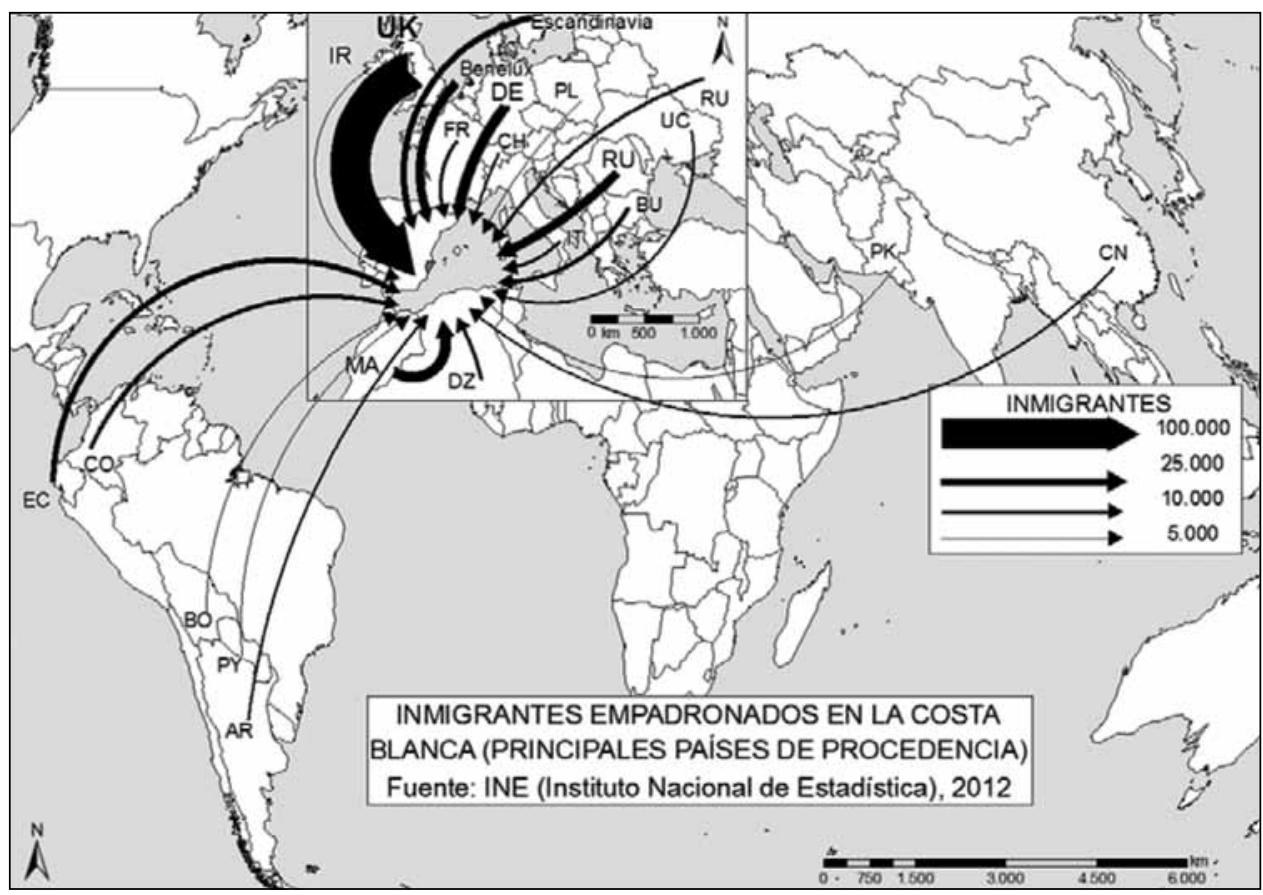

Fuente: INE (Instituto Nacional de Estadística). (http://www.ine.es/jaxi/tabla.do?path=/t20/e245/p04/a2012/ 10/\&file $=00003008 . p x \&$ type $=$ pcaxis $\& L=0)$

Por lo tanto, a medida que las colonias de migrantes residenciales de jubilados se iban creando, se formaban grupos sociales con una lengua y una cultura comunes. Y, conforme las colonias de jubilados crecían, cada vez más profesionales de su mismo país se unían a ellas. Estos profesionales pueden también considerarse como migrantes residenciales, aunque son más jóvenes y no han migrado como meros consumidores, sino como trabajadores en activo. Con el fin de mantener su nuevo estilo de vida necesitan trabajar, por lo general en pequeñas empresas como autónomos (Benson y O’Reilly, 2009: 611). Muchos de ellos lo hacen en el sector turístico y/o prestando servicios a los migrantes jubilados (hoteles, restaurantes, bares, talleres de mecánica, agencias inmobiliarias, periodistas, médicos, arquitectos, etc.). Los avances en la tecnología de las telecomunicaciones permiten que sus opciones de trabajo sean cada vez más amplias.

Conforme cada grupo de extranjeros crece, crea enormes colonias (de ingleses, alemanes, holandeses, noruegos, etc.), y cada colonia se convierte en una pieza de un mosaico multicultural (Piqueras, 2011: 202-203). A medida que estas colonias son mayores, su influencia también lo es. Estos colonos participan en la vida social y política de España, al menos a nivel municipal (en 2009 la Comunitat Valenciana tenía 30 concejales extranjeros y Andalucía, 18). 
Mientras que los migrantes por trabajo se encuentran dispersos por toda España, en función de la población y el PIB de cada provincia, los migrantes residenciales se concentran en las regiones del Mediterráneo y en las Islas Canarias. La Costa Blanca es el área con mayor porcentaje de inmigrantes residenciales: un 35\%, frente a un $65 \%$ de inmigrantes por trabajo. Si observamos el origen de los inmigrantes que viven en la Costa Blanca (fig. 4), y lo comparamos con el origen de los inmigrantes para el conjunto de España (fig. 3), observamos diferencias significativas. Mientras que en la Costa Blanca el mayor grupo de expatriados proviene del Reino Unido (ergo, son residenciales), en el conjunto de España los inmigrantes proceden en su mayoría de Rumanía, Marruecos y Sudamérica (es decir, son migrantes por trabajo). La Costa del Sol es el área con el segundo porcentaje más alto de inmigrantes residenciales (34\%). Le siguen Canarias (33\%), Balears (22\%), Granada (21\%), Almería (20\%), la Costa Brava (17\%) y la Costa de la Luz (17\%). Como vemos, los mayores porcentajes de migrantes residenciales se encuentran en las provincias costeras de clima mediterráneo, incluyendo Canarias y la Costa de la Luz. Mientras tanto, en la España interior el porcentaje de migrantes residenciales es significativamente menor: $11 \%$ en Sevilla, $7 \%$ en Madrid, o $4 \%$ en Zaragoza.

Figura 5

\section{DIFERENCIAS ENTRE LOS MIGRANTES POR TRABAJO Y RESIDENCIALES EN ESPAÑA}

\begin{tabular}{|c|c|c|}
\hline \multicolumn{3}{|c|}{ INMIGRANTES EN ESPAÑA } \\
\hline POR TRABAJO & \multicolumn{2}{|c|}{ RESIDENCIALES } \\
\hline $\begin{array}{l}\quad 80 \% \text { del total. } \\
\text { Casi todos menores de } 55 \text { años. } \\
\text { Proceden de países más pobres. } \\
\text { Se establecen en toda la }\end{array}$ & \multicolumn{2}{|c|}{$\begin{array}{l}20 \% \text { del total. } \\
\text { Casi la mitad supera los } 55 \text { años. } \\
\text { Procede de países más ricos. } \\
\text { Se establecen principalmente en la costa mediterránea. } \\
\text { Buscan un nuevo estilo de vida. }\end{array}$} \\
\hline $\begin{array}{l}\text { geografía española. } \\
\text { Huyen de la pobreza. } \\
\text { Buscan trabajo como } \\
\text { asalariados en servicios, } \\
\text { construcción, industria o } \\
\text { agricultura. }\end{array}$ & $\begin{array}{l}\text { Menores de } 55 \text { años } \\
\text { Autoempleados. } \\
\text { Muchos dan servicio a los } \\
\text { migrantes residenciales } \\
\text { retirados de su misma } \\
\text { nacionalidad. }\end{array}$ & $\begin{array}{l}\text { Retirados. } \\
\text { Viven de sus pensiones y } \\
\text { ahorros. }\end{array}$ \\
\hline
\end{tabular}

Rodríguez (2004: 240) afirma que la movilidad residencial desde el norte hacia el sur de Europa se explica porque el clima meridional es más suave - temperatura media agradable en invierno, mayor proporción de días de sol y lluvias relativamente escasas - , lo que hace posible tener un estilo de vida más relajado y hacer más actividades al aire libre. ${ }^{4}$

4 Nos hemos puesto en contacto con algunos migrantes residenciales estudiantes de castellano en la Escuela de Idiomas de Benidorm, y les hemos preguntado acerca de las razones por las que se trasladaron a España. La mayoría de ellos dijo que el clima era el factor principal, entre los cuales Susan Williams, de 62 años, 
Figura 6

ESPAÑA: EVOLUCIÓN DE LOS MIGRANTES RESIDENCIALES ENTRE 1991 Y 2013

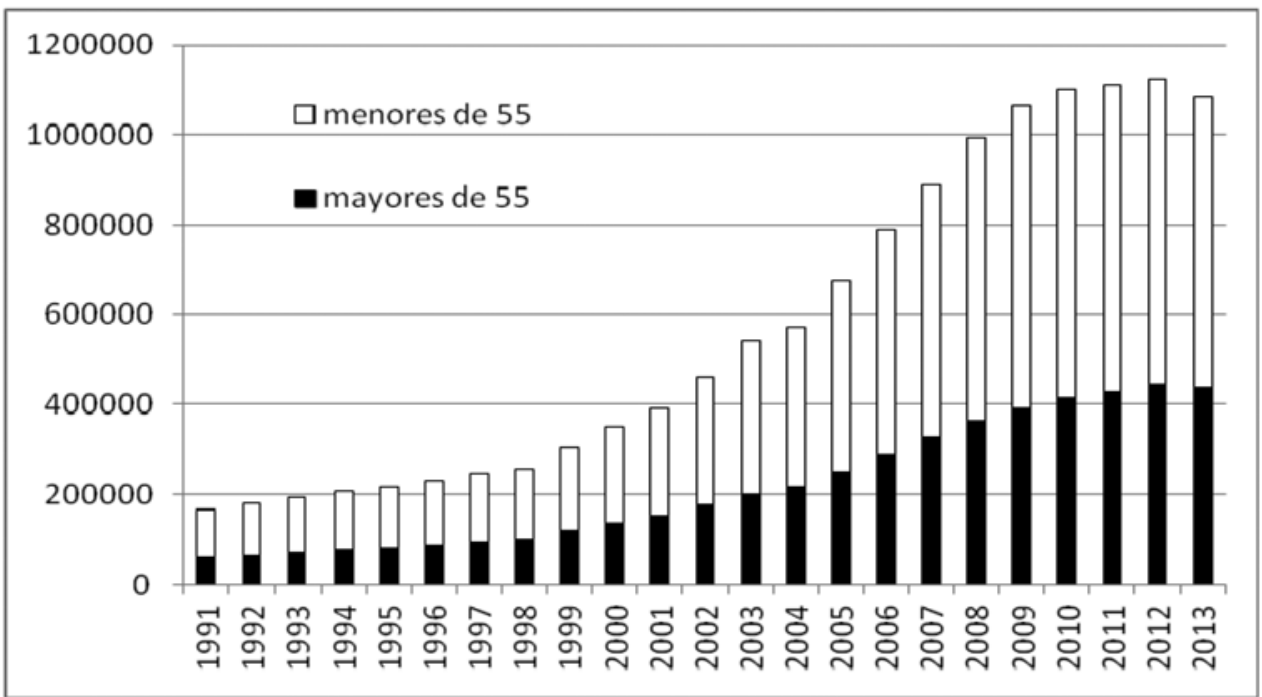

Fuente: elaboración propia a partir de datos del INE. Revisión del padrón municipal/continuo (población extranjera por país de nacionalidad, edad (grupos quinquenales) y sexo). Para 1991: censo de población y viviendas (población extranjera por país de nacionalidad, sexo y edad). Para 1992-1995 y 1997: estimaciones a partir de interpolación lineal.

España es, con diferencia, el país mediterráneo con mayor número de migrantes residenciales. En 2012 estos suponían alrededor de 1.125.000 (INE, 2013), una cifra muy superior a la de otros países europeos de clima mediterráneo. Según el ISTAT (2013), en 2010 había 150.000 migrantes residenciales censados en Italia. Según el SEF (2013), había alrededor de 60.000 en Portugal. Y según EL.STAT (2013), había alrededor de 50.000 en Grecia en 2001 (no pudimos encontrar datos más recientes). Hay que aclarar que estas diferencias tan notables podrían estar acentuadas por el uso de distintas metodologías en cada país.

\subsection{El gran hogar del jubilado europeo}

De los 1.125.000 migrantes residenciales censados en España en 2012, casi 450.000 (41\%) eran mayores de 55 años (es decir, jubilados o prejubilados) (figura 6). Además, este colectivo (tanto de mayores como de menores de 55 años) ha experimentado un cre-

exenfermera en Inglaterra y ahora jubilada y residente en Benidorm, que comentó que en la Costa Blanca hay un promedio de 300 días cálidos y soleados frente a los 300 días fríos y lluviosos en Inglaterra. También explicó otros factores de atracción como la amabilidad de los españoles, la playa, la montaña, el paisaje, los pueblos, las ciudades (para ir de compras) y las buenas carreteras y autopistas. Añadió que le encantaba el estilo de vida relajado del sur de España y el hecho que su familia pudiera venir a visitarla por vacaciones o en escapadas, gracias a las buenas conexiones aéreas de Liverpool y Manchester con Alicante. 
cimiento impresionante durante los últimos veinte años, coincidiendo con el desarrollo de la burbuja inmobiliaria y del urbanismo expansivo. Por lo que respecta a mayores de 55 años, en 1991 solo había 60.000 migrantes residenciales, frente a los cerca de 450.000 en 2012 (fig. 6). Aunque desde 2008 España está atravesando una grave crisis económica, el número de migrantes residenciales retirados en este país no dejó de crecer hasta el 1 de enero de 2012. Los datos provisionales del INE muestran, con todo, que el 1 de enero de 2013 , la cantidad de migrantes residenciales en España habría caído por primera vez (-8.880) desde que existen datos oficiales de inmigración.

Por lo que se refiere a la distribución geográfica de los migrantes residenciales retirados, el $80 \%$ de ellos vive en la costa mediterránea, un 13,7\% en Canarias y un 1,5\%, en la Andalucía atlántica (ambas zonas también de clima mediterráneo). El 5,3\% restante vive en el centro, el oeste o el norte de España. Las áreas en las que prefieren asentarse son la Costa Blanca (que reúne al 35,5\% de todos los migrantes residenciales retirados en España), la Costa del Sol (el 17,1), Canarias (el 13,5), la costa catalana (el 7,1\%), Balears (el 6,6), el Mediterráneo andaluz sin la Costa del Sol (el 5), Murcia (el 4,6) y la costa valenciana sin la Costa Blanca (el 3,4) (fig. 7).

En cuanto a la nacionalidad de los migrantes residenciales retirados, en la figura 7 hemos distinguido cinco procedencias, de acuerdo con su idioma de origen: inglés (que incluye a británicos y una pequeña colonia irlandesa); alemán (alemanes, una pequeña colonia de austriacos y una considerable de suizos, la mayor parte de la cual de lengua alemana); neerlandés (holandeses, belgas - que en su mayoría hablan también holandés - y luxemburgueses); lenguas escandinavas (las colonias sueca y noruega son considerables); y los hablantes de lenguas romances (franceses e italianos).

Los migrantes residenciales retirados de origen francés e italiano (60.742, el 14\% del total español) constituyen la mayoría en todo el litoral catalán, debido a la proximidad geográfica de los países de origen con Cataluña. Los escandinavos $(36.726,8,4 \%$ del total español), se concentran en la Costa Blanca y la Costa del Sol. ${ }^{5}$ Los del Benelux (37.844; $8,6 \%$ del total) también se concentran principalmente en la Costa Blanca, y también, en menor medida, en la Costa del Sol' ${ }^{6}$.Los germanófonos (95.426, 21,8\% del total) prefieren la Costa Blanca, pero también hay grandes colonias de ellos en las islas, tanto en Canarias como en Balears (en ambos archipiélagos constituyen la mayor colonia de migrantes residenciales retirados). ${ }^{7}$ Casi la mitad de los migrantes residenciales que viven en España (47,3\%) proceden de Gran Bretaña (e Irlanda) (207.274). Los anglófonos prefieren asentarse en la Costa Blanca y, en menor medida, en la Costa del Sol. ${ }^{8}$ Constituyen la mayor colonia de migrantes residenciales retirados en todo el sur y este de la costa española, salvo en Cataluña y las islas (fig. 7).

$5 \quad$ El 39\% de los migrantes residenciales retirados escandinavos en España viven en la Costa Blanca, y el $36 \%$, en la Costa del Sol.

$6 \mathrm{El} 47 \%$ de los migrantes residenciales retirados del Benelux viven en la Costa Blanca, y el 14\%, en la Costa del Sol.

7 El 32\% de los migrantes residenciales retirados germanohablantes viven en la Costa Blanca, el $21 \%$ en Canarias y el $13 \%$ en Balears.

8 El 35,5\% de los migrantes residenciales retirados angloparlantes viven en la Costa Blanca, y el 17\%, en la Costa del Sol. 


\section{Figura 7 \\ ESPAÑA: MIGRANTES RESIDENCIALES CENSADOS POR NACIONALIDAD Y POR PROVINCIA DE RESIDENCIA (1 DE ENERO DE 2013)}

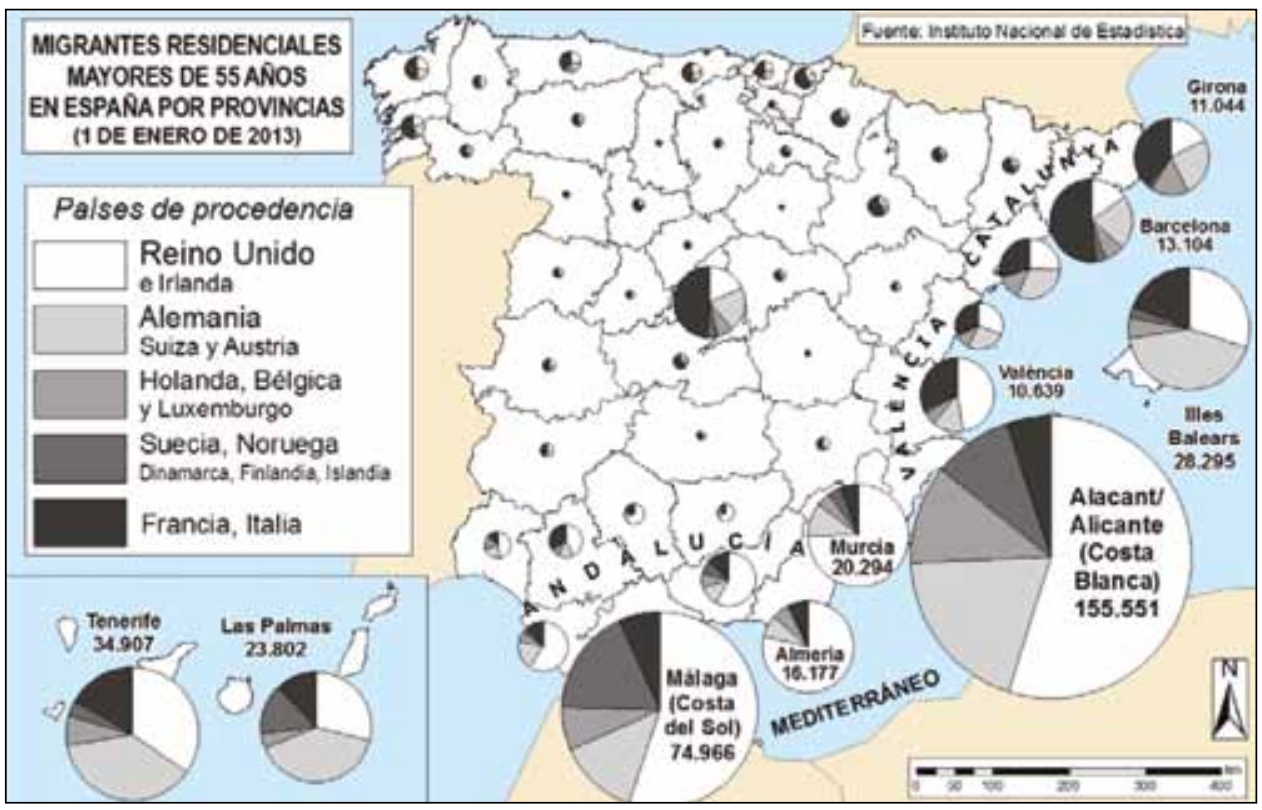

Fuente: INE. Elaboración propia. (http://www.ine.es/jaxi/tabla.do?path=/t20/e245/p04/a2012/10/\&file=0ccaa006. px\&type $=$ pcaxis $\& \mathrm{~L}=0$ )

Como podemos ver en la figura 7 , la costa mediterránea española se ha convertido, para cientos de miles de migrantes residenciales retirados, en el gran hogar del jubilado europeo, de la misma manera que lo es Florida para Nortemérica. Millones de americanos del frío norte y centro de los Estados Unidos (y del aún más frío Canadá) eligen pasar sus años de jubilación en la soleada Florida (Walters, 2002). Las buenas comunicaciones y la proximidad relativa (3 horas entre Miami y Nueva York) entre la península caribeña y los estados del norte favorecen la migración residencial de millones de jubilados norteamericanos. De acuerdo con Smith y House (2006: 4) hay tres tipos de migrantes residenciales retirados en la Florida: los que viven allí todo el año (stayers), los que lo hacen la mayor parte del año (sunbirds) y los que residen allí solo en invierno (snowbirds).

Los migrantes residenciales retirados europeos tienen su propia Florida en la España mediterránea. Lugares como Mallorca, la Costa del Sol y la Costa Blanca están bien conectados y a poco más de dos horas en avión desde Londres, Amsterdam o Düsseldorf. Según O’Reilly (1996) y Betty y Cahill (1996), los migrantes residenciales británicos en la Costa del Sol se pueden clasificar en tres tipos principales: los que, como los stayers de Florida, viven de forma permanente en España; los que, como los sunbirds floridenses, pasan aquí la mayor parte del año; y los que, al igual que los snowbirds, pasan la mayor parte del año en sus países de origen. 


\subsection{Contribución de los migrantes residenciales al urbanismo expansivo}

Cuando vivían en sus países noreuropeos de origen, la mayoría de los migrantes residenciales que actualmente residen en España lo hacía en casas unifamiliares, bajo un patrón caracterizado por el urbanismo expansivo. Además de por el cambio y la mejora en el estilo de vida y por las 3.000 horas de sol al año (1.500 en sus países de origen), los migrantes residenciales también se sentían atraídos por el relativamente bajo precio de las viviendas unifamiliares en las regiones mediterráneas. Dicho coste era relativamente bajo incluso después de la subida de precios a causa de la burbuja especulativa. Como consecuencia de la demanda solvente por parte de los migrantes residenciales jubilados, un número creciente de viviendas unifamiliares se ha construido en la costa mediterránea española en los últimos 20 años, lo que ha contribuido a la difusión del urbanismo expansivo.

Con el beneplácito de las autoridades locales, los promotores inmobiliarios construyeron miles de viviendas unifamiliares (aisladas o adosadas) en la costa mediterránea, y con ellas llegaron los problemas que suelen ir asociados al urbanismo expansivo: destrucción del paisaje y del medio ambiente, congestión del tráfico, riesgo de inundaciones, escasez de agua, etc. A diferencia de la Europa situada al norte del paralelo $45^{\circ}$, la precipitación en la cuenca mediterránea es baja y hay una escasez crónica de agua, por lo que tradicionalmente el poblamiento se había concentrado alrededor de lugares donde había fuentes o ríos. En la actualidad, y a pesar de los embalses, trasvases y desalinizadoras, el problema de la carestía hídrica se ve agravado por la difusión del urbanismo expansivo, gran derrochador de agua. Así, el consumo de agua en las zonas turísticas donde prima el urbanismo expansivo, como Torrevieja, duplica el consumo de zonas turísticas de urbanismo compacto, como Benidorm (Vera, 2006: 166).

Según CORINE 2006, Madrid y Barcelona son las provincias donde se da un porcentaje más alto de urbanismo expansivo $(6,6 \%$ y 4,45\%, respectivamente, del territorio de dichas provincias corresponde a este tipo de uso del suelo, fig. 8). En ambos casos, esto se debe a la elevada población (6,5 millones en Madrid, y 5,5 en Barcelona) y a la notable riqueza acumulada en ambas áreas, lo que implica que un número importante de personas que viven allí tienen suficiente poder adquisitivo para residir en una casa unifamiliar. Las personas que viven en urbanizaciones alrededor de Madrid y Barcelona son principalmente españolas. Durante la burbuja inmobiliaria española, muchas de ellas abandonaron su antigua casa en la ciudad compacta para trasladarse a una zona suburbana.

Después de Madrid y Barcelona, las más altas tasas de urbanismo expansivo se dan en las provincias costeras turísticas, lo que demuestra que hay una clara relación en España entre número de migrantes residenciales y cantidad de suelo urbano expansivo. En Alacant (Costa Blanca), que, como hemos visto, tiene más migrantes residenciales que cualquier otra provincia de España, el urbanismo expansivo constituye el 4,16\% de todas las coberturas del suelo. Según datos SIOSE (2009), algunas zonas de esta provincia albergan un porcentaje muy alto de urbanismo expansivo: en la Vega Baja llega al 8\% (y en su principal ciudad, Torrevieja, al 21\%) (figura 10), mientras que en la Marina Alta es del 10\% (en poblaciones como Dénia y Xàbia este porcentaje se eleva al 25\%, y en Calp, al 40\%) 


\section{Figura 8 \\ RELACIÓN ENTRE MIGRANTES RESIDENCIALES Y URBANISMO EXPANSIVO EN ESPAÑA POR PROVINCIAS}

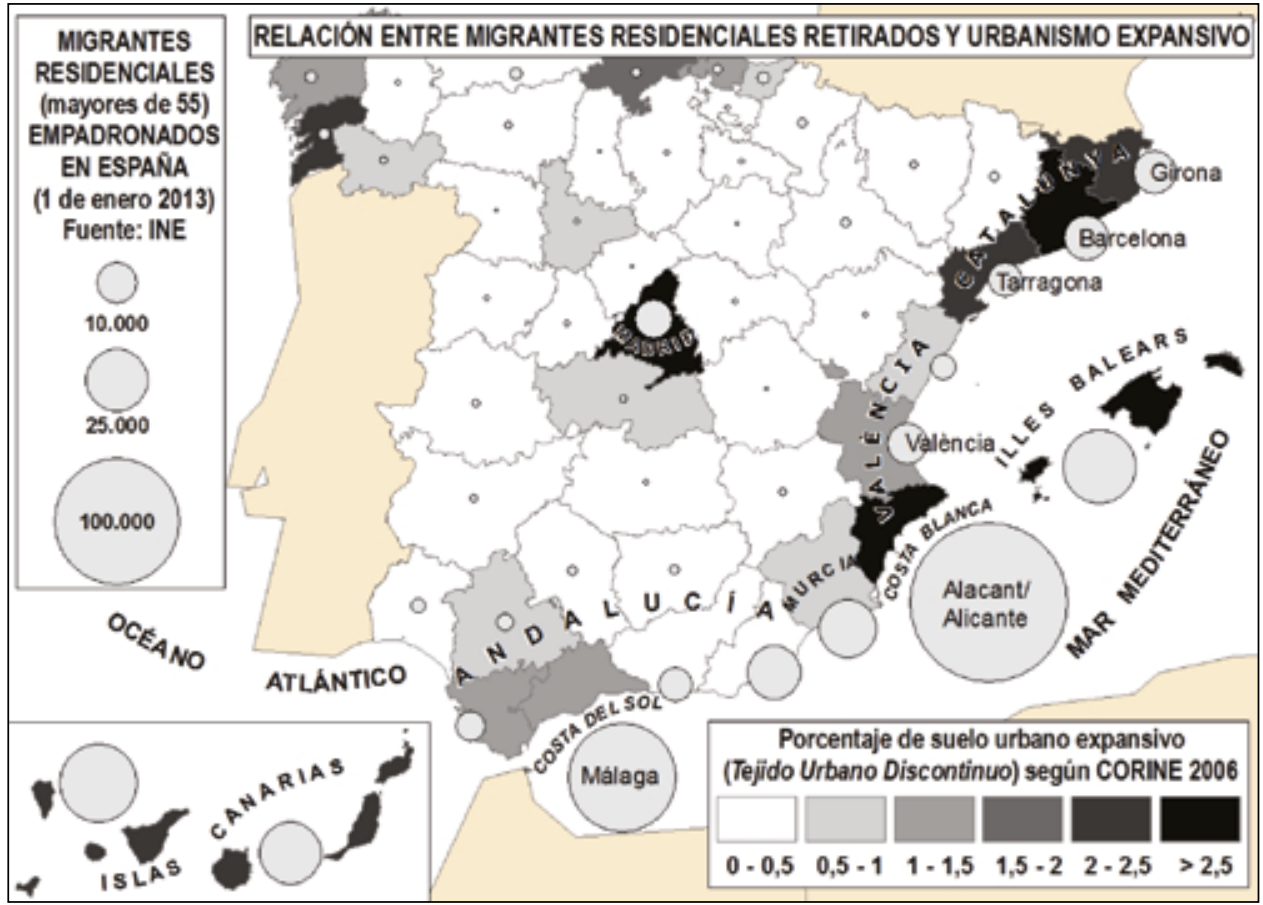

Fuente: elaboración propia a partir de CORINE e INE (http://www.ine.es/jaxi/tabla.do?path=/t20/e245/p04/ a2012/10/\&file $=0$ ccaa006.px\&type $=$ pcaxis $\& L=0$ ).

(figura 9) (Membrado, 2011: 435-436). Tras la Costa Blanca, la Costa del Sol, Balears y Canarias son las áreas con mayor número de migrantes residenciales. También en estas áreas el urbanismo expansivo ocupa un porcentaje notable de las coberturas del suelo $(1,5 \%, 2,97 \%$ y $2,26 \%$, respectivamente). Las provincias de Girona $(2,14 \%)$ y Tarragona $(2,38 \%)$ tienen un menor porcentaje de migrantes residenciales, y su alto porcentaje de urbanismo expansivo está ligado a su proximidad a Barcelona.

\section{PARADIGMA DEL URBANISMO EXPANSIVO EN LA EUROPA MERIDIONAL}

\subsection{El caso de la Costa Blanca}

La demanda solvente por parte de migrantes residenciales de viviendas unifamiliares que siguen patrones urbanos expansivos ha implicado que el Mediterráneo español sea hoy una de las zonas del sur de Europa donde este tipo de desarrollo urbano ha crecido más y más rápido. Solo la Costa Blanca, marca turística de la provincia de Alacant, albergaba 
en 2012 más migrantes residenciales (254.000) que la suma de los que había en Italia (150.000) y Portugal (68.000). Para hacernos una idea del peso del urbanismo expansivo y de los migrantes residenciales en la Costa Blanca, hay que considerar que las cinco comarcas costeras que la componen la provincia de Alacant constituyen solo el $0,68 \%$ de todo el territorio español, pero albergan el 7,7\% de su suelo urbano expansivo y no menos de un tercio de todos sus migrantes residenciales retirados.

El mayor desarrollo del urbanismo expansivo ligado a la migración residencial en la Costa Blanca se encuentra al norte (la Marina, fig. 9) y al sur (la Vega Baja, fig. 10) de esta. Ambas zonas se benefician de su relativa proximidad al aeropuerto de Alacant, que está muy bien comunicado (más de 40 vuelos diarios) con las islas británicas y también tiene conexiones regulares con Escandinavia, Benelux, Alemania y Rusia. De hecho, muchos de los migrantes residenciales en la Costa Blanca suelen viajar regularmente a sus países de origen por razones familiares, sanitarias, laborales, etc.

En la figura 9 vemos cómo durante la burbuja inmobiliaria española se produjo una notable expansión del urbanismo expansivo en la Marina, que pasó de $8.000 \mathrm{Ha}$ en 1987 a 11.500 en 2006. Su desarrollo fue particularmente significativo en el área prelitoral (a 3-7 km del mar), ya que las zonas costeras (a 0-3 km del mar) estaban ya saturadas desde antes de 1987. El mismo fenómeno de urbanización del prelitoral, descrito por Crawford et al. (2013: 236), y por Kambly y Moreland (2009:11), ha ocurrido en áreas turísticas homologables de Carolina del Norte y la Florida.

En la figura 10 se observa la difusión del urbanismo expansivo en la Vega Baja, donde pasó de solo 1.600 Ha en 1987 a nada menos que 6.300 en 2006. Las viviendas unifamiliares se desarrollaron tanto en el litoral como, sobre todo, en el prelitoral. La relativa lejanía de las urbanizaciones al mar (3-7 km) se ve compensada por otros atractivos, como los campos de golf (Mata, 2007: 42): de hecho, 7 de los 14 campos de golf existentes en la Costa Blanca se encuentran en el prelitoral de la Vega Baja. Además, en 2012 esta misma área albergaba los tres municipios españoles con mayor porcentaje de extranjeros: San Fulgencio (78\% de sus 12.522 hab. son extranjeros), Rojales (77\% de 22.006) y Algorfa (72\% de 4.755). Los migrantes residenciales suponen más de la mitad de la población allí, y el idioma inglés se habla más que cualquier otro, incluyendo el castellano.

El crecimiento urbano casi sin límites del urbanismo expansivo en la Costa Blanca fue impulsado por la fuerte demanda de los migrantes residenciales (especialmente de británicos), ${ }^{9}$ favorecido por los ayuntamientos, y promovido por grandes empresas constructoras y financieras, muchas de las cuales se enriquecieron considerablemente durante la burbuja especulativa inmobiliaria, si bien no pocas de ellas, debido a su mala gestión,

9 Miles de jubilados británicos se hipotecaron comprando casas en la costa española entre 1999 y 2008 , cuando $1 £$ equivalía a $1,5 €$, con lo cual podían adquirirlas a precios relativamente bajos y residir aquí con pensiones modestas. En ese momento una vivienda de $200.000 €$ les costaba a ellos unos $133,000 £$ al cambio y una pensión de $1.000 £$ equivalía a una en España de $1.500 €$. Desde 2008, sin embargo, la depreciación de la libra frente al euro ha recortado un $30 \%$ el valor adquisitivo de los migrantes residenciales británicos. Muchos no ganan lo suficiente para vivir en España y pagar una hipoteca, y se ven forzados a regresar al Reino Unido. Otros están atrapados porque vendieron sus casas en Gran Bretaña, compraron una en el Mediterráneo español, y ahora no la pueden vender, ni siquiera a un precio mucho más bajo del que pagaron por ella. 
Figura 9

MAPA DIACRÓNICO DEL URBANISMO EXPANSIVO EN LA MARINA

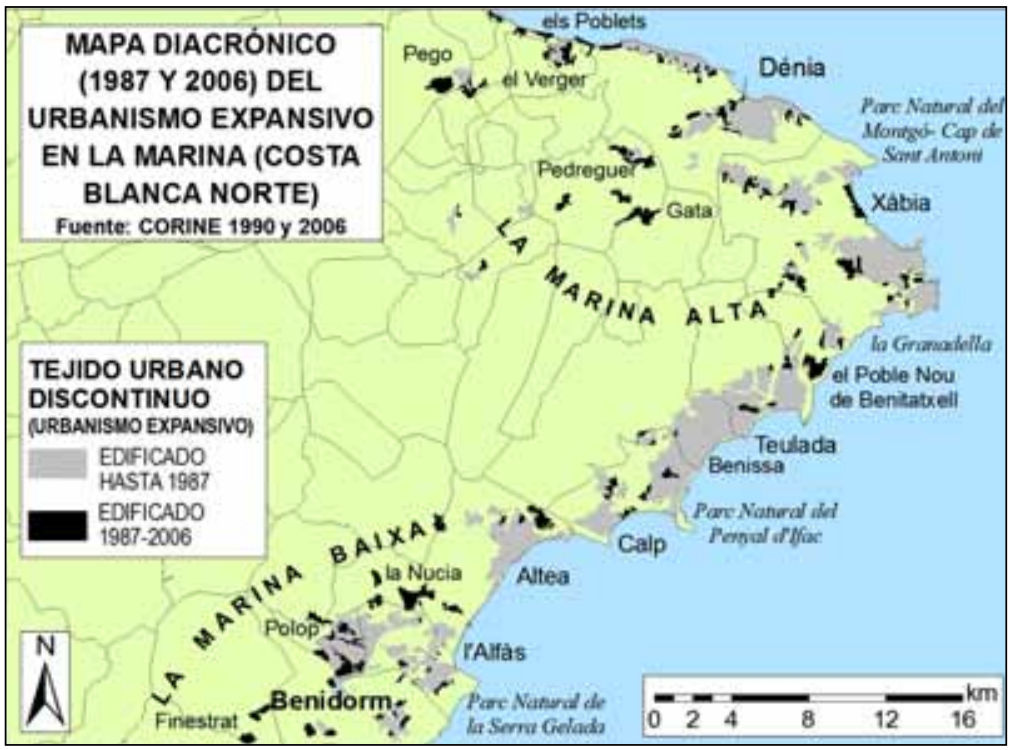

Fuente: CORINE.

Figura 10

MAPA DIACRÓNICO DEL URBANISMO EXPANSIVO EN LA VEGA BAJA

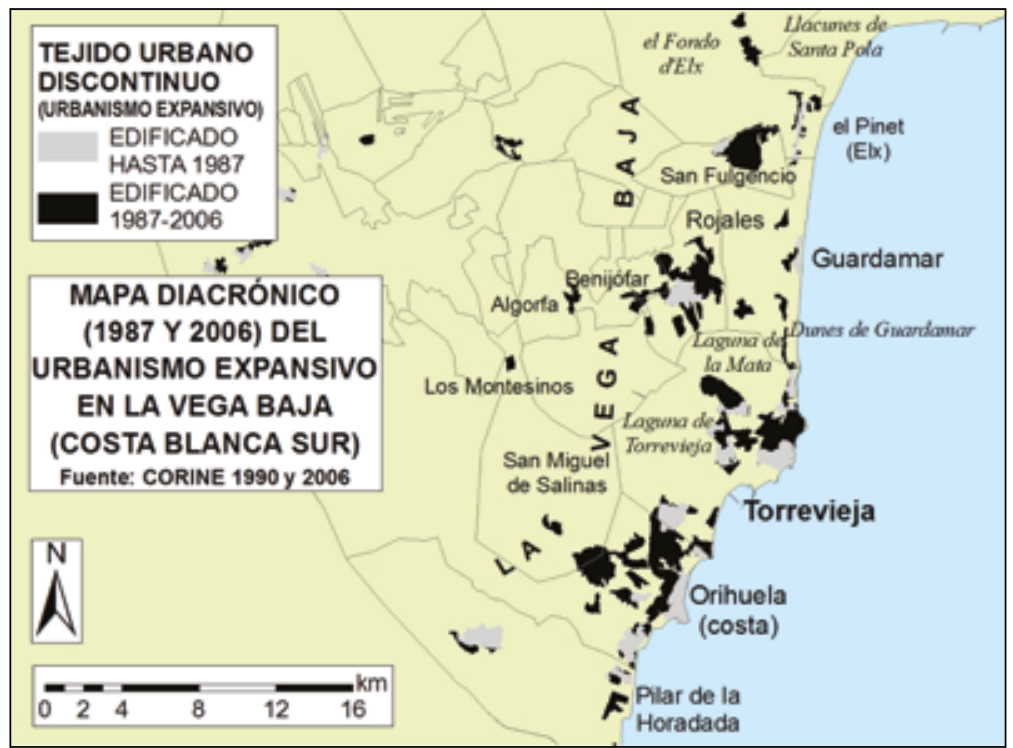

Fuente: CORINE. 
se arruinaron tras su estallido en $2007 . .^{10}$ Pero antes de 2007 ya se había construido gran cantidad de tejido urbano discontinuo, producto del urbanismo expansivo, y ello había comportado una serie de ventajas e inconvenientes para las áreas de asentamiento de los migrantes residenciales jubilados.

\subsection{Consecuencias de la migración residencial de jubilados}

Por lo que respecta a los efectos positivos de la llegada de migrantes residenciales jubilados, cabe señalar que esta hace aumentar la demanda de servicios a escala local, atrayendo así nueva mano de obra, lo que a su vez incrementa aún más el número de consumidores locales (Walters, 2002: 51). Los beneficios económicos se pueden observar en el aumento de la población de los lugares de acogida: Torrevieja, donde hay un $30 \%$ de migrantes residenciales, ha cuadruplicado su población en apenas veinte años (de 25.000 hab. en 1991 a más de 100.000 en 2011); Rojales, con un 75\% de migrantes residenciales, triplicó su población en el mismo período (de 5.000 a 20.000 hab.) y San Fulgencio, con un $80 \%$ de migrantes residenciales, la multiplicó por 7,5 (1.600 hab. en 1991 y 12.000 en 2011). Otro de los beneficios, citado por Walkers (2002: 52), es que los jubilados tienen ingresos basados en gran medida en las pensiones, y en caso de recesión a escala local, los jubilados se ven menos afectados que el resto de la población y siguen repercutiendo positivamente en la economía local. ${ }^{11}$

Entre los inconvenientes de la migración residencial de jubilados, su afluencia masiva comporta el peligro de la superpoblación en las áreas de acogida, lo que significa más congestión del tráfico, excesiva urbanización, etc. (Walters, 2002: 52). Esta migración además puede sobresaturar los suministros (de agua, electricidad o saneamiento) y puede afectar al medio ambiente. Aunque Walters se refiere a los efectos de la migración de jubilados en la Florida, Arizona, California y otros estados del Sun Belt de EEUU, también describe fidedignamente dichos efectos en zonas como la Costa Blanca. La urbanización allí ha sido tan desmesurada que algunas áreas de urbanismo expansivo se han convertido en zonas de urbanismo expansivo compacto, por mucho que pueda parecer un oxímoron hablar de un patrón de desarrollo urbano a la vez expansivo y compacto. ${ }^{12}$ No menos paradójico resulta el hecho que los migrantes residenciales, que se trasladaron al sur con el fin de

10 Muchas entidades bancarias gastaron tanto en la compra de solares con la intención de edificarlos que cuando estalló la burbuja inmobiliaria tuvieron que ser intervenidas o nacionalizadas. El capital invertido por dichas entidades bancarias e inmobiliarias en la compra de suelo para promoción y construcción de nuevas viviendas era tanto español como extranjero. Debido a la crisis global, una parte considerable del capital foráneo inyectado en los bancos españoles para proyectos inmobiliarios no ha podido ser devuelto, lo que ha repercutido en que España sufra medidas de ajuste económico más severas, y los españoles padezcan más los efectos de la crisis, que los ciudadanos de otros países vecinos.

11 Sin embargo, como hemos dicho en la nota 9, los ingresos de los británicos (más de la mitad de todos los migrantes residenciales en la Costa Blanca) se han visto afectados negativamente por la devaluación de la libra respecto al euro.

12 Densely packed sprawl es la expresión utilizada en un artículo de The Washington Post (Blaine, 2005) para describir el área urbana de Los Ángeles, origen y paradigma del urbanismo expansivo. Según este artículo, Los Ángeles es más denso que algunas grandes ciudades del este de EEUU que, aparentemente, tienen un urbanismo más compacto, como Nueva York o Washington. Este proceso es similar a lo que sucede en la España mediterránea. Según datos de 2009 de SIOSE, la densidad de población (habitantes por km² urbanizado) en Tor- 


\section{Figura 11 \\ URBANISMO EXPANSIVO COMPACTO EN ROJALES (VEGA BAJA)}

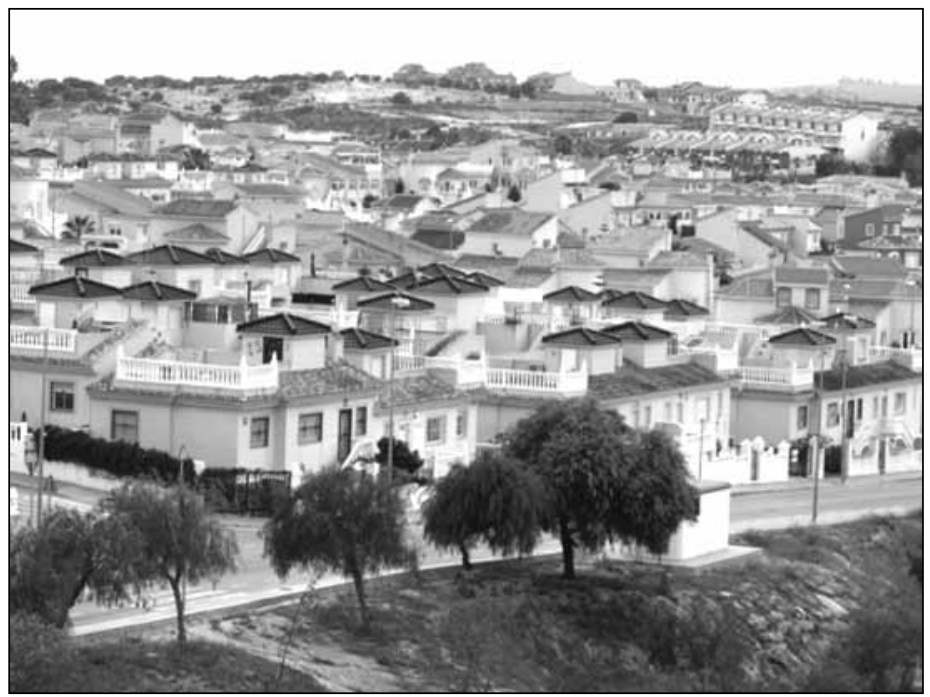

Imagen de Antoni Martínez i Bernat.

aumentar su calidad de vida, han visto cómo sus destinos se han visto degradados por la superpoblación y la superurbanización, causadas en gran parte por la llegada masiva de nuevos migrantes residenciales (Benson y O'Reilly, 2009: 621). ${ }^{13}$

Otro inconveniente citado por Walters (2002: 52) es que los migrantes residenciales retirados suelen gozar de buena salud cuando se mudan a su nuevo hogar, pero a medida que envejecen se vuelven cada vez vulnerables, de manera que una consecuencia a largo plazo de este tipo de migración es la saturación de las infraestructuras sanitarias. Algunos estudiosos consideran que la migración internacional resulta beneficiosa para los jubilados suficientemente ricos y experimentados frente a las molestias que puede implicar. Otros piensan que los jubilados entran en una situación de riesgo al emigrar, ya que se vuelven vulnerables ante posibles problemas de salud o financieros y, si se ven en la necesidad de regresar a casa, se quedan aislados al haber perdido los contactos sociales con los que contaban en su país de origen (Russell et al., 1998).

revieja - paradigma del urbanismo expansivo en España-es de 4.634 hab. $/ \mathrm{km}^{2}$ ), mientras que en Benidorm — paradigma de urbanismo compacto - es de 5.011, sólo un poco más que en Torrevieja.

13 Algunos de los primeros migrantes noreuropeos llegados hace ya algunas décadas a la Marina se instalaron en un emplazamiento rural y aislado, lejos de las grandes urbanizaciones litorales. Sin embargo, a raíz de la aprobación de la ley del suelo de 1998, muchos se vieron despojados de su particular remanso de tranquilidad, debido a que promotores y autoridades municipales aprobaron y ejecutaron planes urbanísticos desmesurados sobre dichos terrenos rústicos. Parte de estos migrantes residenciales pioneros denunciaron ante la Unión Europea lo que consideraban que era un abuso urbanístico, una destrucción del paisaje y una vulneración de los derechos de los propietarios (Burriel, 2009b, 19). 
Figura 12

AGRESIÓN AL MEDIO AMBIENTE EN BENITATXELL, (MARINA ALTA)

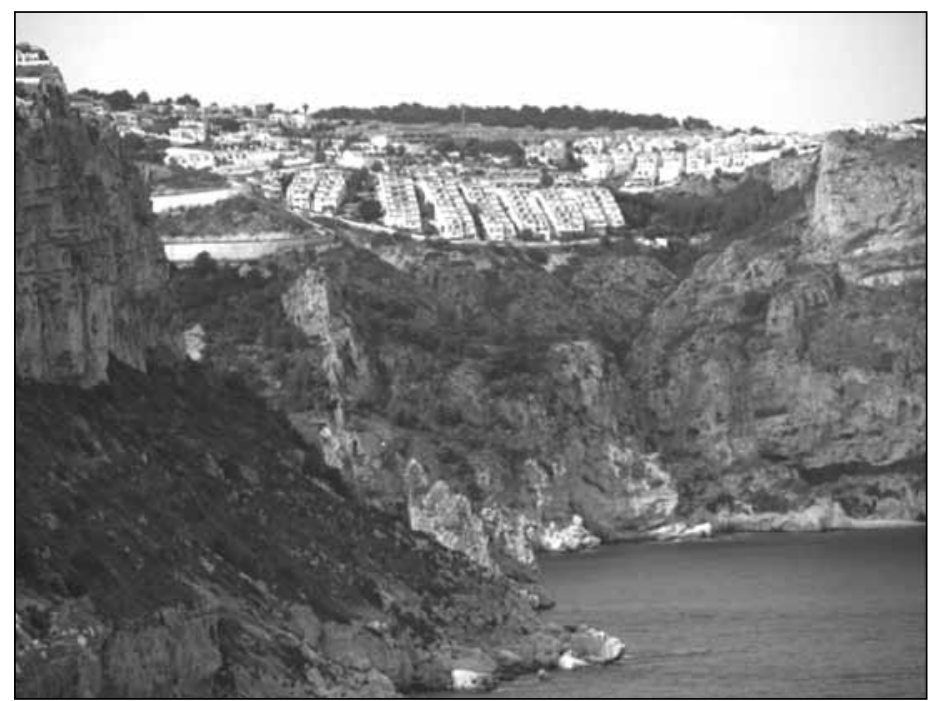

Imagen de Antoni Martínez i Bernat.

Figura 13

USO INTENSIVO DEL SUELO EN CALP (MARINA ALTA)

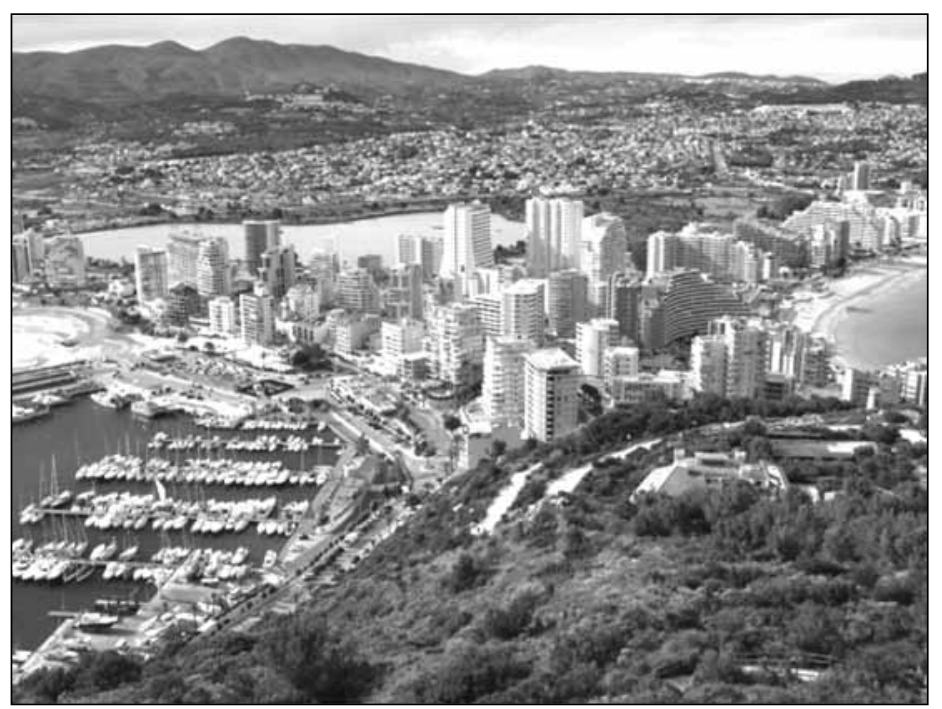

Imagen de Antoni Martínez i Bernat. 
Respecto a las consecuencias sociales de la migración de jubilados, hay que decir que la urbanización de la Costa Blanca no ha sido solo excesiva, sino poco favorable a la integración, ya que ha creado enormes áreas suburbanas aisladas de los centros urbanos y de la población autóctona (figura 11). ${ }^{14}$ La mayoría de estas urbanizaciones carecen de transporte público eficiente, lo que limita la movilidad de muchos de sus residentes, que tienden a permanecer dentro de la urbanización, con pocas opciones de entretenimiento. Por otra parte, el aislamiento y la distancia a los servicios básicos (centro de salud, comisaría de policía, etc.) aumentan la percepción de inseguridad en estos barrios ghetto.

Finalmente, por lo que se refiere al impacto ambiental, las consecuencias para la Costa Blanca de la migración internacional de jubilados han sido muy graves. El daño al paisaje y el medio ambiente, sobre todo cerca del litoral, pude considerarse como irreparable (fig. 12). ${ }^{15}$ La Ley de Suelo aprobada por el gobierno español en 1998, que establecía que todo suelo no protegido era urbanizable (Rullán, 2011: 182), ha tenido un fuerte impacto en algunas zonas del Mediterráneo español, como es el caso de la Costa Blanca. En esta zona hay algunas áreas costeras protegidas: Montgó-Cap de Sant Antoni, el Penyal d'Ifac (fig. 13), ${ }^{16}$ la Serra Gelada o la lagunas de Santa Pola, la Mata y Torrevieja (figuras 9 y 10). Podría pues parecer que no hay escasez de áreas protegidas donde disfrutar de la naturaleza. El problema es que todos estos parques, de dimensiones no muy grandes, están parcial o completamente rodeados de zonas urbanas. No hay transición alguna entre los parques naturales y las superficies urbanizadas (fig. 13). Debido a su clima, paisaje, cultura y medio ambiente, la costa mediterránea es un lugar codiciado por los promotores. Los gobiernos - a nivel local, regional o nacional - que deberían haber protegido la costa contra los excesos urbanísticos, han permitido, por acción u omisión, a los promotores construir sin apenas trabas, hasta el punto que una parte considerable de un paisaje mediterráneo único ha sido irreversiblemente desfigurada. Ello constituye hoy un serio inconveniente para competir en un mercado tan dinámico y abierto como el turístico, en el que se considera cada vez más la calidad del territorio como parte de la calidad del producto (Mata, 2007: 40-44).

\section{CONCLUSIONES}

El mediterráneo español ha experimentado un desarrollo incontrolado del urbanismo expansivo a lo largo de las últimas dos décadas. Este crecimiento fue significativamente impulsado por la demanda solvente por parte de migrantes residenciales, en su mayoría jubilados del norte de Europa, que quisieron y pudieron costearse una vivienda unifamiliar

14 En la figura 11 se aprecian las viviendas unifamiliares de Rojales compactamente esparcidas a lo largo de $\mathrm{km}^{2}$ carentes de jardines, transporte y otros servicios públicos.

15 En la figura 12 se observa como las viviendas literalmente cuelgan de un acantilado, lo que desfigura el paisaje del Morro del Castell (Benitatxell).

16 En la figura 13 se observa en primer término el Parque Natural del Penyal d'Ifac. En segundo término vemos el suelo urbano compacto edificado en altura y un puerto deportivo. En tercer lugar, las salinas protegidas de Calp. En cuarto lugar, una gran área de urbanismo expansivo. Como se puede observar, no existe una zona de transición entre el (relativamente escaso) suelo protegido y el suelo urbanizado. 
en la soleada y relajada atmósfera del Mediterráneo español. Así, el número de migrantes residenciales retirados empadronados en España se multiplicó por 7,5 entre 1991 y 2012. Una gran mayoría de ellos (95\%) eligió las regiones españolas litorales de clima mediterráneo para pasar sus años de jubilación.

Esta masiva afluencia de migrantes residenciales supuso a corto plazo una considerable riqueza para las regiones de acogida. Por un lado, generó notables ingresos para las administraciones (local, regional, estatal) a través de los impuestos. Por otro, benefició a los promotores privados y, en menor medida, a parte de la población local, que pasó a prestar servicios para los recién llegados. Sin embargo, la falta de una planificación urbana adecuada que hubiera permitido controlar los excesos de los promotores generó una urbanización desmesurada en las áreas de acogida. De esta forma, muchos de los inmigrantes que se habían trasladado al sur esperando mejorar su calidad de vida, entre otras cosas por el hecho de vivir rodeados de naturaleza y tranquilidad, finalmente se vieron frustrados (en parte) por la excesiva edificación de sus barrios suburbanos. Otra consecuencia de esta enorme urbanización ha sido el daño irreversible causado al medio ambiente y al paisaje a través de la pérdida de campos, montañas y bosques.

El progreso económico que el desarrollo del urbanismo expansivo generó en el corto plazo puede tener consecuencias económicas impredecibles en el largo plazo. Algunas áreas suburbanas del Mediterráneo español están demasiado edificadas, y de ello se derivan algunos inconvenientes. Por una parte, estas áreas presentan los mismos inconvenientes que cualquier otra área suburbana: alto consumo de agua, energía y tierra per cápita, dependencia absoluta del vehículo privado y destrucción del paisaje y el medio ambiente. Por otra, tienen además los problemas propios de las zonas compactas (congestión de tráfico, densificación del suelo urbano) pero sin ninguna de sus ventajas (transporte público, instalaciones públicas, zonas verdes, tiendas cerca de casa, etc.). Además, los municipios están cada vez más endeudados y apenas pueden proporcionar servicios básicos, como limpieza o policía, a dichas áreas suburbanas.

Dadas las crecientes deficiencias de la densamente edificada costa mediterránea española, los migrantes residenciales jubilados que ahora viven allí podrían no tener reemplazo en unos años. Si los políticos locales quieren evitarlo, deberían comenzar a trabajar de una manera más racional y sostenible. Por ejemplo, las urbanizaciones periféricas deberían estar mejor conectadas con los cascos urbanos a través de transporte público, paseos peatonales y caminos para bicicletas. Además, los suburbios deberían contar con áreas verdes y servicios públicos. Estas medidas podrían mejorar la cohesión territorial y social entre los migrantes residenciales, que se verían así más motivados para superar las barreras del idioma y la cultura, y la gente local, que deberían dejar de considerar a los migrantes residenciales como meros consumidores de servicios.

La figura 14 es un esquema en que se explican las causas que favorecieron la urbanización masiva en la España mediterránea, así como las causas de la migración internacional de jubilados, los motivos por los cuales el Mediterráneo español es un polo de atracción para los jubilados y, finalmente, las consecuencias positivas y negativas de dicha migración y cambio de uso del suelo. 


\section{Figura 14 \\ CAUSAS DE LA MIGRACIÓN RESIDENCIAL DE JUBILADOS Y DEL CAMBIO DE USO DEL SUELO. VENTAJAS E INCONVENIENTES DERIVADOS DE ESTA}

\begin{tabular}{|c|c|c|}
\hline \multicolumn{3}{|c|}{ Diversos factores que favorecen la urbanización es España: } \\
\hline \multicolumn{3}{|c|}{ Burbuja inmobiliaria, desarrollo urbano masivo, multitud de viviendas disponibles } \\
\hline \multicolumn{3}{|c|}{ Financiarización: uso de inmuebles como activo financiero } \\
\hline \multicolumn{3}{|c|}{ Dependencia de entidades locales de ingresos provenientes de la construcción } \\
\hline \multicolumn{3}{|c|}{ Promoción en los países de origen de los compradores } \\
\hline \multicolumn{3}{|c|}{$\downarrow$} \\
\hline $\begin{array}{c}\text { Causas por las que emigran los } \\
\text { jubilados } \\
\text { noreuropeos }\end{array}$ & \multicolumn{2}{|c|}{$\begin{array}{c}\text { Causas por las que los jubilados noreuropeos } \\
\text { emigran al Mediterráneo español }\end{array}$} \\
\hline \multirow[b]{2}{*}{ Mejora de la calidad de vida } & \multicolumn{2}{|r|}{ Vuelos directos y a bajos precio } \\
\hline & \multicolumn{2}{|r|}{$\begin{array}{l}\text { Precio de las viviendas unifamiliares } \\
\text { relativamente barato }\end{array}$} \\
\hline Mayor longevidad & \multicolumn{2}{|c|}{$\begin{array}{l}\text { Buenas infraestructuras de transporte, sanitarias, } \\
\text { etc. }\end{array}$} \\
\hline $\begin{array}{l}\text { Ahorros y pensiones pública y } \\
\text { privadas para gastar }\end{array}$ & \multicolumn{2}{|c|}{$\begin{array}{c}\text { Clima soleado, vida al aire libre, mar, montaña, } \\
\text { beneficios para la salud }\end{array}$} \\
\hline Mejora tecnológica global & \multicolumn{2}{|c|}{ Ritmo de vida relajado, gastronomía, vino, fiestas } \\
\hline \multicolumn{3}{|c|}{$\downarrow$} \\
\hline \multicolumn{3}{|c|}{ Consecuencias de la migración residencial de jubilados } \\
\hline \multicolumn{2}{|c|}{ Positivas } & Negativas \\
\hline \multicolumn{2}{|c|}{$\begin{array}{c}\text { Incremento de la demanda de servicios para atender a } \\
\text { los migrantes residenciales. }\end{array}$} & $\begin{array}{l}\text { Superpoblación, congestión de tráfico, } \\
\text { excesiva densificación urbana. }\end{array}$ \\
\hline \multicolumn{2}{|c|}{ Esto atrae nueva mano de obra. } & $\begin{array}{l}\text { Saturación de las instalaciones (agua, } \\
\text { electricidad, saneamiento, consultorios } \\
\text { médicos, etc.). }\end{array}$ \\
\hline \multicolumn{2}{|c|}{$\begin{array}{l}\text { Aumento de la población y riqueza en el } \\
\text { Mediterráneo español. }\end{array}$} & $\begin{array}{l}\text { Destrucción o deterioro del medio } \\
\text { ambiente. }\end{array}$ \\
\hline \multirow{3}{*}{\multicolumn{2}{|c|}{$\begin{array}{l}\text { Los jubilados dependen principalmente de sus } \\
\text { pensiones, procedentes de países solventes } \\
\text { noreuropeos, con lo cual siguen aportando riqueza } \\
\text { en sus municipios de acogida aunque haya crisis } \\
\text { económica en España. }\end{array}$}} & $\begin{array}{l}\text { Aislamiento social y cultural de los } \\
\text { migrantes residenciales. }\end{array}$ \\
\hline & & $\begin{array}{l}\text { Endeudamiento y quiebra de muchos } \\
\text { jubilados }\end{array}$ \\
\hline & & Corrupción e indisciplina urbanísticas \\
\hline
\end{tabular}

Por lo menos desde 1991 (el primer año para el cual tenemos registros estadísticos) hasta 2011 el número de migrantes residenciales no dejó de crecer en España. Sin embargo, los datos provisionales del INE a 1 de enero de 2013 muestran que en 2012, a pesar de la enorme caída en los precios de la vivienda, la cantidad de migrantes residenciales registrados en España disminuyó en casi 9.000 personas. 
¿Será 2012 solo una excepción en la creciente afluencia de migrantes residenciales retirados a España? ¿O tal vez el 2012 será un punto de inflexión, el año en que el número de migrantes residenciales retirados empezará a estabilizarse alrededor de los 400.000-450.000? ¿O quizá 2012 marcará incluso el comienzo del exilio de los migrantes residenciales hacia otros destinos más atractivos? A pesar de la fuerte seducción que la España mediterránea todavía ejerce sobre cientos de miles de migrantes residenciales, los excesos urbanísticos, la falta de servicios, la percepción de inseguridad o el daño ambiental irreparable pueden suponer una pesada hipoteca sobre el futuro del Mediterráneo español.

\section{BIBLIOGRAFÍA}

BENSON, M. y O'REILLY K. (2009): «Migration and the search for a better way of life: a critical exploration of lifestyle migration», The Sociological Review, vol. 57(4), pp. 608-625.

BETTY, C. y CAHILL, M. (1996): «Social and health problems of older British expatriates on the Costa del Sol», en Convergence or Diversity? Social policy in Europe, Social Policy Association Conference.

BLAINE, H. (2005, 11 de agosto): «Out West, a Paradox: Densely Packed Sprawl», en The Washington Post. Disponible en http://www.washingtonpost.com/wp-dyn/content/article/2005/08/10/AR2005081002110.html

BURRIEL, E.L. (2008). «La década prodigiosa del urbanismo español (1997-2006)». Scripta Nova, vol. XII, no 270 (64). Disponible en: http://www.ub.edu/geocrit/sn/ sn-270/sn-270-64.htm.

BURRIEL, E.L. (2009a). «La planificación territorial en la Comunidad Valenciana (19862009)». Scripta Nova,vol. XIII, n 306. Disponible en: http://www.ub.edu/geocrit/sn/ sn-306.htm.

BURRIEL, E. L. (2009b). «La Unión Europea y el urbanismo valenciano. ¿Conflicto jurídico o político?, Boletín de la Asociación de Geógrafos Españoles, no 49, pp. 5-23.

CASADO, M.A. (2006): «Retiring to Spain: An Analysis of Differences among North European Nationals», Journal of Ethnic and Migration Studies, vol. 32 (8), ,pp. 1.3211.339.

CRAWFORD T.W., BRADLEY, D.E. y MARCUCCI D.J. (2013): «Impacts of InMigration and Coastal Amenities on Housing Growth in Coastal North Carolina, United States», Population, Space and Place, vol. 19, pp. 223-238. DOI: 10.1002/ psp. 1695.

EL.STAT (Helleniké Statistiké Arché) (2013): Foreigners by citizenship and age groups (2001). Disponible en: http://www.statistics.gr/portal/page/portal/ESYE/PAGEthemes?p_param $=A 1602 \&$ r_param $=S A M 07 \& y \_p a r a m=2001 \_00 \&$ mytabs $=0$

EMF (European Mortgage Federation) (2009): Hypostat 2009: a review of Europe's mortgage and housing markets. Disponible en: http://www.law.berkeley.edu/files/bclbe/ Hypostat_2009_europe_s_mortgage_and_housing_markets.pdf

ENTWISLE B. y STERN P. (Ed.) (2005): Population, Land Use, and Environment: Research Directions. Washington DC. National Academy Press. 
GAJA, F. (2008): «El «tsunami urbanizador» en el litoral mediterráneo. El ciclo de hiperproducción inmobiliaria 1996-2006», Scripta Nova, vol. VIII, nº 270 (66). Disponible en: http://www.ub.es/geocrit/sn/sn-270/sn-270-66.htm.

GILlHAM, O. (2002): The Limitless City: a Primer on the Urban Sprawl Debate, Island Press, Washington DC, 309 pp.

GUSTAFSON, P. (2009): "Your home in Spain: residential strategies in international retirement migration», en Lifestyle Migration. Expectations, Aspirations and Experiences(Benson, M. y O’Reilly, K., ed.). Farnham. Ashgate.

HIERRO, M. y MAZA, A. (2010): «Per capita income convergence and internal migration in Spain: Are foreign-born migrants playing an important role?», Papers in Regional Science, vol. 89 (1), pp. 89-107.

HOF, A. y BLÁZQUEZ, M. (2013). «The Linkages between Real Estate Tourism and Urban Sprawl in Majorca (Balearic Islands, Spain)», Land vol. 2, pp. 252-277.

HUETE, R. (2005): «Factores de atracción de Alicante como destino residencial: el punto de vista de los residentes europeos», en Turismo residencial y cambio social. Nuevas perspectivas teóricas y empíricas, pp. 375-390 (Mazón, T. y Aledo, A., ed.). Alicante. Aguaclara.

HUETE, R. (2009): Turistas que llegan para quedarse. Una explicación sociológica sobre la movilidad residencial. Alicante, Universidad de Alicante.

HUETE, R. y MANTECÓN, A. (2011): «Más allá del turismo: movilidad residencial europea y nuevos núcleos urbanos». Boletín de la Asociación de Geógrafos Españoles, $\mathrm{n}^{\circ} 56$, pp. 111-128.

HUETE, R. y MANTECÓN, A. (2013): «La migración residencial de noreuropeos en España». Convergencia. Revista de Ciencias Sociales, vol. 20, (61), pp. 219-245, Universidad Autónoma del Estado de México.

IGN (Instituto Geográfico Nacional) (2006): SIOSE. Manual de fotointerpretación. Madrid. Ministerio de Fomento. Disponible en: http://www.ign.es/siose/Documentacion/Guia_Tecnica_SIOSE/070322_Manual_Fotointerpretacion_SIOSE_v1_2.pdf.

INE (Instituto Nacional de Estadística) (2013): «Población por sexo, municipios y nacionalidad». Disponible en: http://www.ine.es/jaxi/menu.do?type=pcaxis\&path=\%2Ft20 $\% 2 \mathrm{Fe} 245 \&$ file $=$ inebase $\& \mathrm{~L}=0$.

ISTAT (Istituto Nazionale di Statistica) (2013): «Provenienza per Nazione europea (2010). Residenti in Italia dall'Europa». Disponible en: http://www.comuni-italiani.it/statistiche/stranieri/europa.html.

KAMBLY, S. y MORELAND, T.R. (2009): «Land cover trends in the Southern Florida Coastal Plain». U.S. Geological Survey Scientific Investigations Report 2009-5054.

KING, R., WARNES, A. y WILLIAMS, A.M. (2000): Sunset Lives: British Retirement Migration to the Mediterranean. Oxford. Berg.

KOCH-SCHULTE, J. (2008): Planning for International Retirement Migration and Expats: a case study of Udon Thani, Thailand. University of Manitoba.

LAMBIN E. y GEIST H. (Ed.) (2006): Land-Use and Land-Cover Change: Local Processes and Global Impacts. Berlin. Springer.

LAPARRA, M. (2011): «Immigration and social policy in Spain: A new model of migration in Europe», Actas del 58th World Statistical Congress. Dublín. 
LÓPEZ, I. y RODRÍGUEZ, E. (2011). «El modelo español». New Left Review, vol 69, pp. 4-29.

MATA, R. (2007): Auge inmobiliario y evolución de los usos del suelo en España. Por una nueva cultura del territorio, lección inaugural del curso académico 2007-2008 de la Universidad Autónoma de Madrid.

MAZÓN, T. (2006): «Inquiring into Residential Tourism: the Costa Blanca case». Tourism and Hospitality Planning \& Development, vol. 3 (2), pp. 89-97.

MAZÓN, T., HUETE, R. y MANTECÓN, A. (Ed.) (2009): Turismo, urbanización y estilos de vida. Las nuevas formas de movilidad residencial. Barcelona. Icaria.

MEMBRADO, J.C. (2011): «SIOSE Valencia 2005: resultados, aplicaciones y comparación con CORINE», Cuadernos de Geografía, no ${ }^{\circ}$ 89, pp. 1-22.

MÓDENES, J. A., BAYONA, J. y LÓPEZ-COLÁS, J. (2013): Immigration and Residential Change in Spain. Population, Space and Place, vol. 19, pp. 294-310.

MUÑOZ, F. (2003): «Lock Living: Urban Sprawl in Mediterranean Cities», Cities, International Journal of Urban Policy and Planning, 6, vol. 20, pp. 381-385.

NAVALÓN, R. (1995): Planeamiento urbano y turismo residencial en los municipios litorales de Alicante. Alicante, Instituto Gil-Albert.

O'REILLY, K. (1996): «A new trend in European migration: contemporary British migration to Fuengirola, Costa del Sol», Geographical Viewpoint, vol. 23, pp. 25-37.

O'REILLY, K. (2000): The British on the Costa del Sol. Transnational identities and local communities. London, Routledge.

O'REILLY, K. (2007): «Intra-European Migration and the Mobility-Enclosure Dialectic», Sociology, vol. 41 (2), pp. 277-293.

O'REILLY, K. (2009): «Migración intraeuropea y cohesión social: el grado y la naturaleza de la integración de los migrantes británicos en España», en Turismo, urbanización y estilos de vida. Las nuevas formas de movilidad residencial (Mazón, T., Huete, R., y Mantecón, A., ed.). Barcelona, Icaria.

O'REILLY, K. y BENSON, M. (2009): «Lifestyle Migration: Escaping to the Good Life?», en Lifestyle Migration. Expectations, Aspirations and Experiences (Benson y O'Reilly, ed.). Farnham, Ashgate.

OLIVER, C. (2007): Retirement Migration: Paradoxes of Ageing. London. Routledge.

PUMAIN, D. (2004): «Urban Sprawl: Is there a French case?», en Urban Sprawl in Western Europe and the United States, pp. 137-157.

RICHARDSON, H. W. y CHANG-HEE, C.B. (Ed.) (2004): Urban Sprawl in Western Europe and the United States, Ashgate, Bodmin.

ROCA, J., BURNS, M.C. y CARRERAS, J.M. (2004): «Monitoring Urban Sprawl around Barcelona's Metropolitan Area with the Aid of Satellite Imagery», 20th ISPRS Congress, Istanbul.

RODRÍGUEZ, V., FERNÁNDEZ-MAYORALAS, G. y ROJO, F. (1998): «European Retirees on the Costa del Sol: A Cross-National Comparison», Population Review, vol 43 (1), pp. 1-36.

RODRÍGUEZ, V., FERNÁNDEZ-MAYORALAS, G. y ROJO, F. (2004): «International Retirement Migration: Retired Europeans Living on the Costa del Sol, Spain», International Journal of Population Geography, vol. 4 (2), pp. 183-200. 
RODRÍGUEZ, V., CASADO, M.A. y HUBER, A. (Ed.) (2005): La migración de europeos retirados en España. Madrid, Consejo Superior de Investigaciones Científicas.

ROMERO, J. (2010): «Construcción residencial y gobierno del territorio en España. De la burbuja inmobiliaria a la recesión». Cuadernos Geográficos de la Universidad de Granada, no 47 , pp. 17-46.

RULLAN, O. (2011): «Urbanismo expansivo en el Estado Español: de la utopía a la realidad», en Geografía: retos ambientales y territoriales: conferencias, ponencias, relatorías, mesas redondas del XXII congreso de geógrafos españoles, Alicante, Universidad de Alicante y Asociación de Geógrafos Españoles, pp. 165-201.

RUSSELL, K., WARNES, A.M. y WILLIAMS, A.M. (1998): «Editorial introduction», International Journal of Population Geography, vol. 4 (2), pp. 87-89.

RUSSELL, K. y PATTERSON, G. (1998) : « Diverse Paths: the Elderly British in Tuscany», International Journal of Population Geography, vol. 4 (2), pp. 157-182.

SEF (Serviço de Estrangeiros e Fronteiras) (2013): Relatório de imigraçao, fronteiras e asilo. Disponible en: http://sefstat.sef.pt/Docs/Rifa_2011.pdf

SHERBININ A., CARR D., CASSELS S. y JIANG L. (2007): «Population and environment», Annual Review of Environment and Resources, vol. 32, pp. 345-373.

SMITH, S.K. y HOUSE M. (2006): «Snowbirds, Sunbirds, and Stayers: Seasonal. Migration of Elderly Adults in Florida», Journal of Gerontology: Social Sciences, vol. 61B (5), pp. 232-239.

VERA, F. y IVARS, J.A. (2003): «Measuring Sustainability in a Mass Tourist Destination: Pressures, Perceptions and Policy Responses in Torrevieja, Spain», Journal of Sustainable Tourism, vol. 11 (2\&3), pp. 181-203.

WALTERS, W. (2002): «Later-Life Migration in the United States: A Review of Recent Research», Journal of Planning Literature, vol. 17 (1), pp. 37-66.

WALKER, R. y SOLECKI, W. (2004): «Theorizing Land-Cover and Land-Use Change: The Case of the Florida Everglades and Its Degradation», Annals of the Association of American Geographers, vol. 94 (2), pp. 311-328.

WARNES, M. y PATTERSON, G. (1998): «British Retirees in Malta: Components of the Cross-National Relationship», International Journal of Population Geography, vol. 4 (2), pp. 113-133.

WILLIAMS, A.M. y PATTERSON, G. (1998): «An Empire Lost but a Province Gained: A Cohort Analysis of British International Retirement in the Algarve», International Journal of Population Geography, vol. 4 (2), pp. 135-155.

WILliAMS, A., KING, R., WARNES, A. y PATTERSON, G. (2000): «Tourism and International Retirement Migration: New Forms of an Old Relationship in Southern Europe», Tourism Geographies, vol. 2 (1), pp. 28-49. 
